\title{
Introduction of emergency contraceptive pills (ECPs) through lady health workers (LHWs) program in Pakistan: Findings of an evaluation study
}

Arshad Mahmood

Population Council

Yasir Bin Nisar

Follow this and additional works at: https://knowledgecommons.popcouncil.org/departments_sbsr-rh

Part of the Community Health Commons, Health Policy Commons, International Public Health Commons, Public Health Education and Promotion Commons, and the Women's Health Commons How does access to this work benefit you? Let us know!

\section{Recommended Citation}

Mahmood, Arshad and Yasir Bin Nisar. 2012. "Introduction of emergency contraceptive pills (ECPs) through lady health workers (LHWs) program in Pakistan: Findings of an evaluation study." Islamabad: Population Council. 


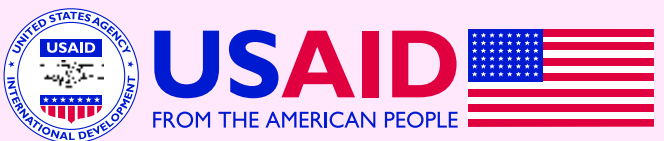

\section{Introduction of Emergency Contraceptive Pills (ECPs) through Lady Health Workers (LHWs) Program in Pakistan}

\section{Findings of an Evaluation Study January 2012}

\section{Authors: \\ Arshad Mahmood Ph.D. Yasir Bin Nisar}





\title{
Introduction of
}

\section{Emergency Contraceptive Pills (ECPs) \\ through Lady Health Workers (LHWs) Program in Pakistan}

\section{Findings of an Evaluation Study}

Report

January 2012

Authors:

Arshad Mahmood Ph.D.

Yasir Bin Nisar

\author{
Research Team: \\ Khan Mohammad \\ Syeda Saman Naz \\ Irfan Masood \\ Mahwish Gul \\ Mohammad Ashraf \\ Nadeem Akhtar
}

(1) Population Council 


\section{(1) Population Council}

The Population Council, an international, non-profit, non-governmental organization established in 1952, seeks to improve the well-being and reproductive health of current and future generations around the world and to help achieve a humane, equitable, and sustainable balance between people and resources.

The Council analyzes population issues and trends; conducts research in the reproductive sciences; develops new contraceptives; works with public and private agencies to improve the quality and outreach of family planning and reproductive health services; helps governments design and implement effective population policies; communicates the results of research in the population field to diverse audiences; and helps strengthen professional resources in developing countries through collaborative research and programs, technical exchange, awards, and fellowships.

The Population Council reserves all rights of ownership of this document. No part of this publication may be reproduced, stored or transmitted in any form by any means-electronic, photocopying, recording or otherwise-without the permission of the Population Council.

For inquiries, please contact:

Population Council

Add: $\quad$ 7, Street 62, F-6/3, Islamabad, Pakistan

Tel: $\quad 92518445566$

Fax: $\quad 92512821401$

Email: info.pakistan@popcouncil.org

Web: http://www.popcouncil.org http://www.falah.org.pk

Layout and Design: Ali Ammad

Published: March, 2012

\section{Disclaimer}

"This study/report is made possible by the generous support of the American people through the United States Agency for International Development (USAID). The contents are the responsibility of the Population Council, Islamabad and do not necessarily reflect the views of USAID or the United States Government." 


\section{Table of Contents}

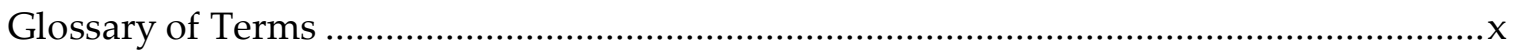

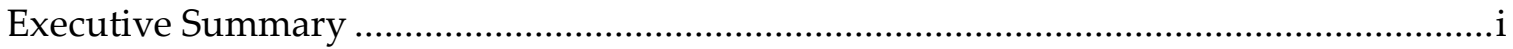

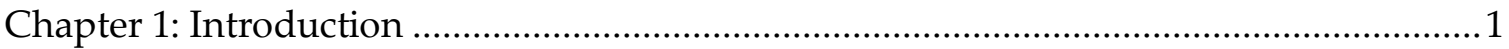

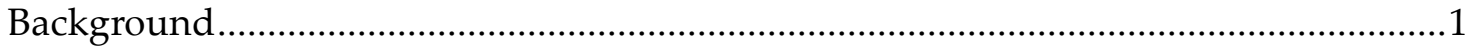

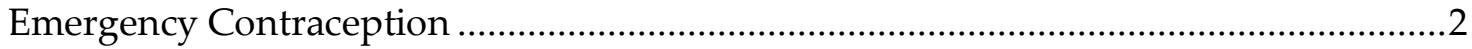

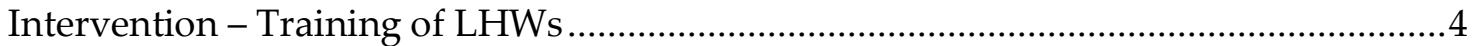

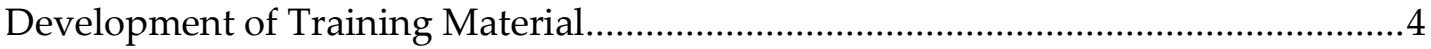

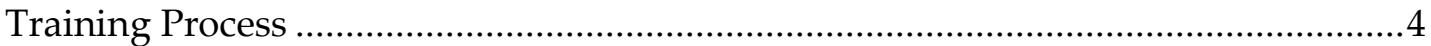

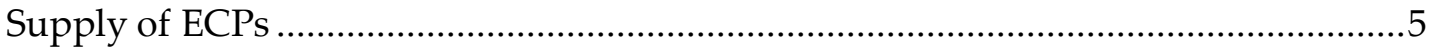

Emergency Contraception Survey …………………………………………………..

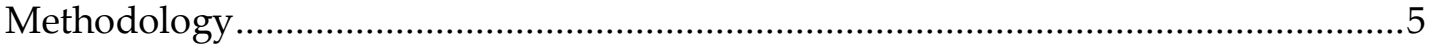

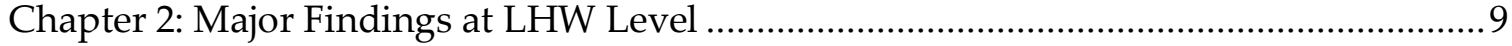

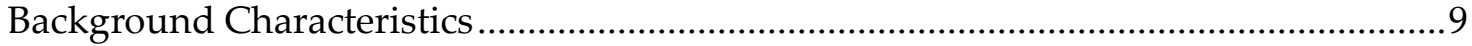

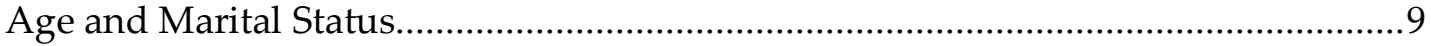

Education and Worked Experience.......................................................................10

ECP Trainings.........................................................................................................

Retention of Knowledge about ECP ……………………………………………...11

Practice of ECP Utility …………………………………………………………....13

Provision and Supply of ECP …………………………………………………....13

Record Keeping of ECP Clients ................................................................................13

Referred to Health Facility for ECP doses ..............................................................14

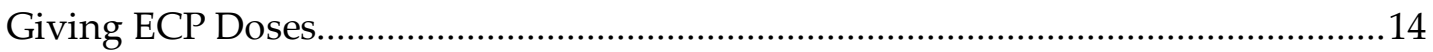

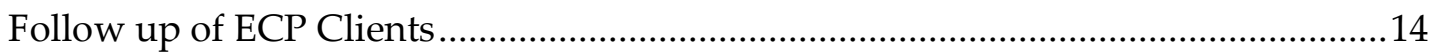

Chapter 3: Major Findings at Married Women of Reproductive Age Level.......................17

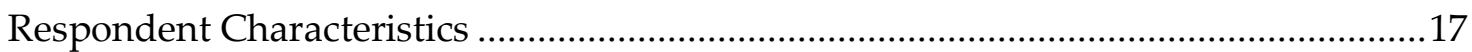

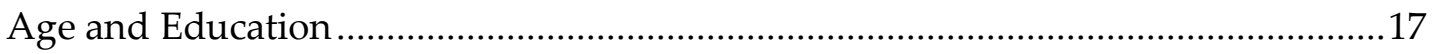

LHW Availability in Community ………………………................................19

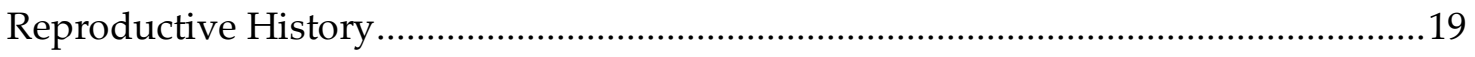

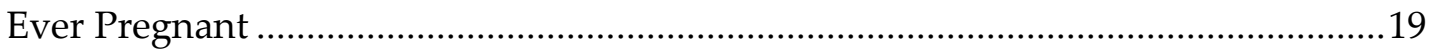

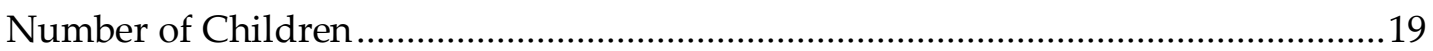

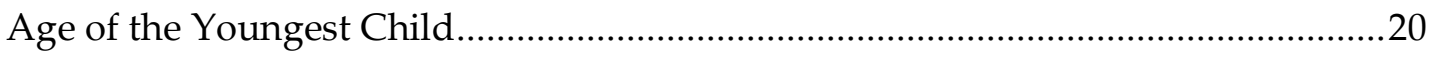

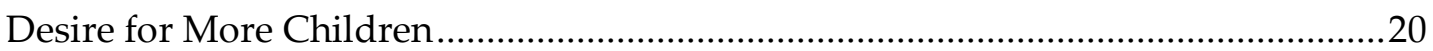




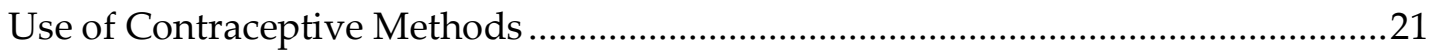

Current Knowledge of ECP Utility ............................................................................... 21

Purpose

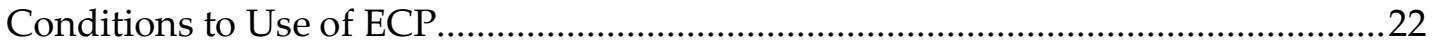

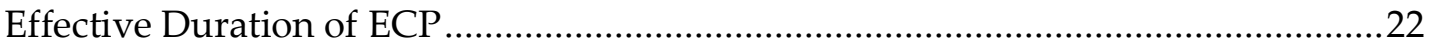

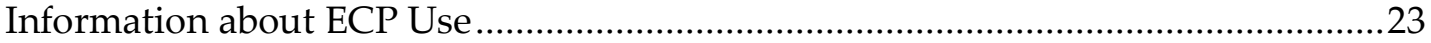

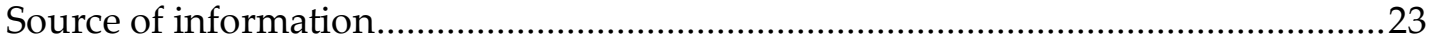

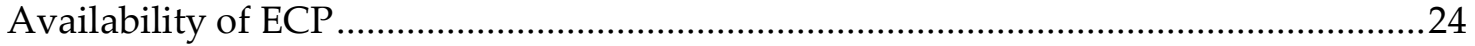

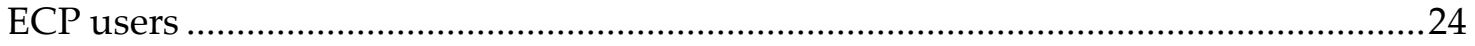

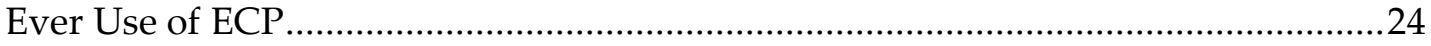

Source of ECP

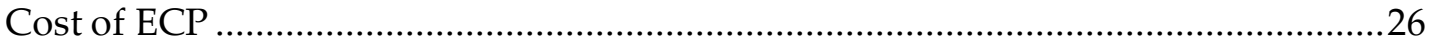

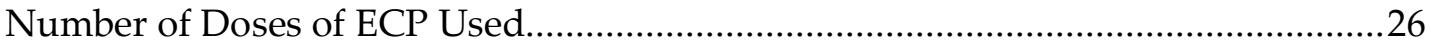

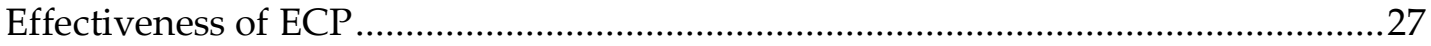

Experienced Side Effects Associated with ECP ....................................................27

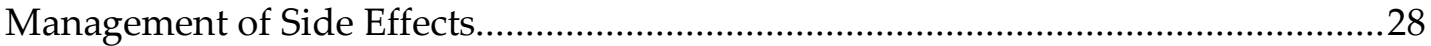

Advice to Others and Desire to Use in Future .......................................................28

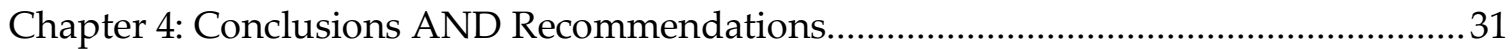

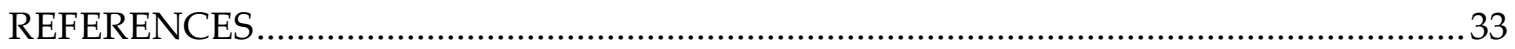




\section{List of Tables}

Table 1.1: Number of LHWs trained in emergency contraception by district....................5

Table 1.2: Results of LHWs and MWRA proposed and interviewed in all the four

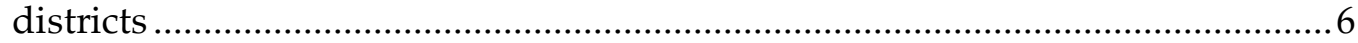

Table 3: Age distribution of MWRA ............................................................................. 17

Table 4: Distribution of MWRA by number of children and mean number of children $(\mathrm{N}=2093)$ 


\section{List of Figures}

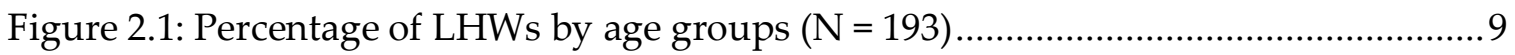

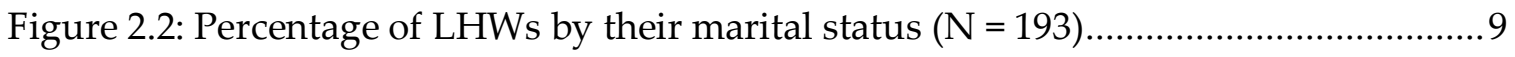

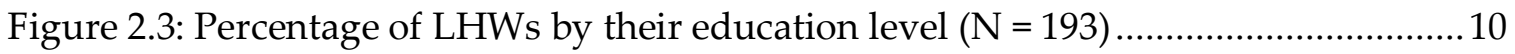

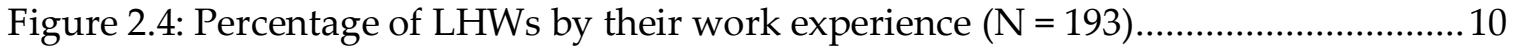

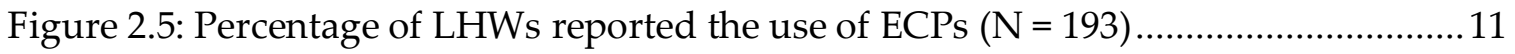

Figure 2.6: Percentage of LHWs reported the common conditions in which ECP

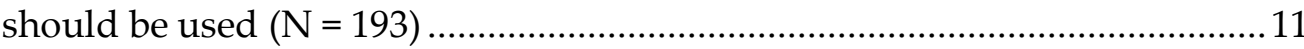

Figure 2.7: Percentage of LHWs reported the correct information about ECP use $(\mathrm{N}=$ 193)

Figure 2.8: Percentage of LHWs who provided ECP doses to women $(\mathrm{N}=193)$ and who received ECP supply from organization regularly $(\mathrm{N}=141) \ldots \ldots \ldots \ldots \ldots . . . .13$

Figure 2.9: Percentage of LHWs who kept ECP client record $(\mathrm{N}=181)$ and who showed list of ECP clients $(\mathrm{N}=64)$.

Figure 2.10: Percentage of LHWs who made referral of women to health facilities for ECP $(\mathrm{N}=181)$ and who showed list of referral women $(\mathrm{N}=19) \ldots \ldots \ldots \ldots \ldots . . . .13$

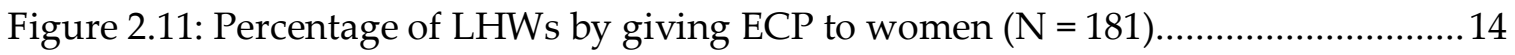

Figure2.12: Percentage of LHWs who contacted the ECP clients and managed side

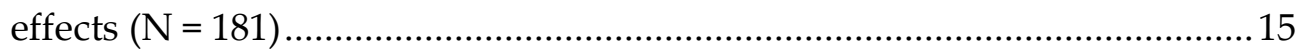

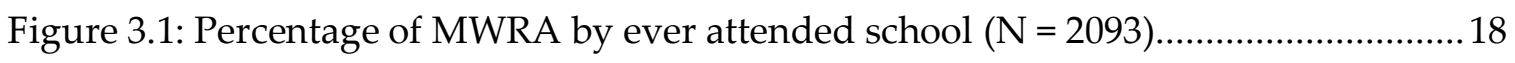

Figure 3.2: Percentage of MWRA by highest level of education attained $(\mathrm{N}=683)$.........18

Figure 3.3: Percentage of MWRA whose husbands attended school $(\mathrm{N}=2093)$............... 18

Figure 3.4: Percentage of MWRA by level of education attained by their husbands (N

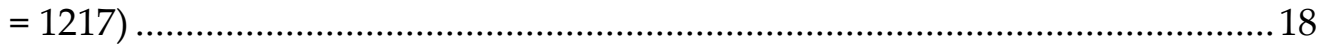

Figure 3.5: Percentage of MWRA by home visits of LHWs $(\mathrm{N}=2081)$............................. 19

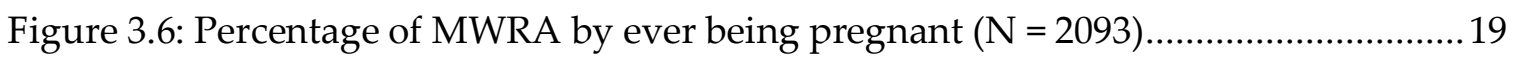

Figure 3.7: Percentage of MWRA by the age of the youngest child $(\mathrm{N}=2093) \ldots \ldots \ldots \ldots . . . . .20$

Figure 3.8: Percentage of MWRA by the time period to wait before the birth of next

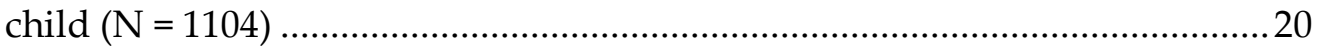

Figure 3.9: Percentage of WMRA by their desire for more children $(\mathrm{N}=2093)$................ 20

Figure 3.10: Percentage of MWRA by contra ceptive method use $(\mathrm{N}=2093)$................... 21

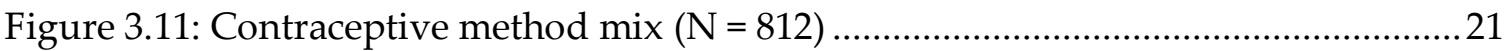

Figure 3.12: Percentage of MWRA who heard about ECP by various purposes of ECP

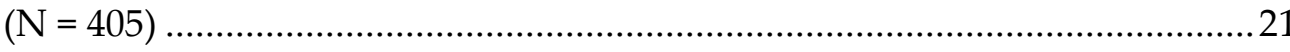

Figure 3.13: Percentage of MWRA reported various conditions for ECP use $(\mathrm{N}=405) \ldots 22$ Figure 3.14: Percentage of MWRA reported the duration of ECP use $(\mathrm{N}=405) \ldots \ldots \ldots \ldots . . . .22$ Figure 3.15: Percentage of MWRA reported information about ECP use $(\mathrm{N}=405) \ldots \ldots . . .23$ 
Figure 3.16: Percentage of MWRA reported the source of information about ECP $(\mathrm{N}=$

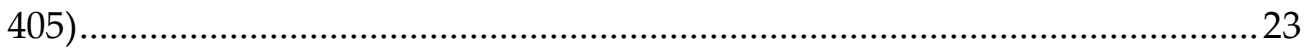

Figure 3.17: Percentage of MWRA by easy availability of ECP $(\mathrm{N}=405) \ldots \ldots \ldots \ldots \ldots \ldots \ldots \ldots \ldots . . .24$

Figure 3.18: Percentage of MWRA by various sources of ECP in communities $(\mathrm{N}=$ 323) 24

Figure 3.19: Percentage of MWRA by ever use of ECP $(\mathrm{N}=405) \ldots \ldots \ldots \ldots \ldots \ldots \ldots \ldots \ldots \ldots \ldots \ldots \ldots . . .25$

Figure 3.20: Percentage of MWRA by various reasons for ECP use $(\mathrm{N}=117)$................... 25

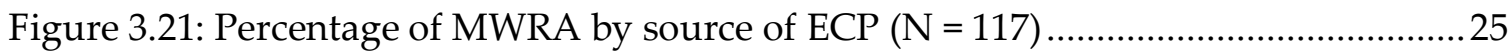

Figure 3.22: Percentage of MWRA by time needed to obtain ECP $(\mathrm{N}=117) \ldots \ldots \ldots \ldots \ldots \ldots \ldots . . .25$

Figure 3.23: Percentage of MWRA by cost of ECP $(\mathrm{N}=117)$............................................. 26

Figure 3.24: Percentage of MWRA reported whether ECP expensive or not $(\mathrm{N}=117) \ldots .26$

Figure 3.25: Percentage of MWRA by number of doses of ECP used last month $(\mathrm{N}=$

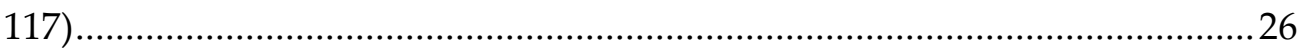

Figure 3.26: Percentage of MWRA by effectiveness of ECP $(\mathrm{N}=117) \ldots \ldots \ldots \ldots \ldots \ldots \ldots \ldots \ldots \ldots \ldots . . .27$

Figure 3.27: Percentage of MWRA by experiencing various side effects $(\mathrm{N}=25) \ldots \ldots \ldots \ldots . . .27$

Figure 3.28: Percentage of MWRA by contacting the providers for the management of side effects $(\mathrm{N}=25)$............................................................................... 28

Figure 3.29: Percentage of MWRA by contacting various providers for the

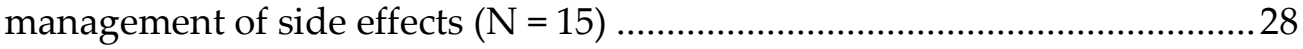

Figure 3.30: Percentage of MWRA who would recommend ECP to others $(\mathrm{N}=117) \ldots . . .29$

Figure 3.31: Percentage of MWRA by their desire to use ECP in future $(\mathrm{N}=117) \ldots \ldots \ldots . . .29$ 


\section{Acknowledgements}

The implementation of the pilot study on Emergency Contraceptive Pills through community health workers was initiated with a study visit to Bangladesh arranged for Government officials to observe the experience of health workers in Bangladesh. We are grateful to Dr. Ubaidur Rob, Country Director, Population Council and Dr M.E. Khan for arranging the visit and briefing the officials on the experience of Bangladesh and India.

The Population Council was primarily responsible for designing, implementing and conducting the final evaluation of the pilot. Many federal and provincial health managers were involved in different stages of the implementation of this study. We would like to thank the following official for helping in conceptualizing the study:

- Dr Assad Hafeez (Executive Director, Health Services Academy)

- Kazi Mujtaba Kamal (National Programme Manager, National Aids Control Programme)

- Dr Tanveer Shaikh (Ex-Provincial Coordinator, National Program for Family Planning and Primary Health Care (NPFP\&PHC))

- Dr Mumtaz Esker (Ex-Director General, Population Program Wing, Planning \& Development Division)

Implementation of the ECP pilot could not have been made possible without the help and cooperation of the NPFPPHC management and we would like to especially acknowledge the contribution of the following:

- Dr Iqbal Ahmed Lehri (National Coordinator)

- Dr Arshad Chandio (Deputy National Coordinator)

- Dr Farah Sabih (Deputy National Coordinator)

- Dr Farrukh Lodhi (Deputy National Coordinator)

- Dr Fouzia Aqeel (Training Coordinator)

- Dr Baqir Hussain Jaffery (Monitoring and Evaluation Officer )

We would like to thank Dr Imdad Khushk and Dr Muhammad Saleem Shaikh for monitoring the field activities during the implementation period. We are indeed most grateful to Dr Gul Rashida for conceptualizing and facilitating its implementation in collaboration of the management of NPFP\&PHC. We would like to express our gratitude to Dr Zeba A. Sathar, Country Director, Population Council, and Dr. Ali Mir, Chief of Party FALAH, for their support and guidance in implementing the study.

The evaluation was designed and conducted by the Monitoring and Evaluation section of the FALAH project. Field teams were trained by the Population Council team consists of Mr. Khan Muhammad, Dr. Waqar Saleem, Ms. Saman Naz, Mr. Muhammad Ashraf, and Ms. Mahwish Gul. Mr. Irfan Masood managed the data entry, data cleaning and 
prepared the tables for this report. Mr. Nadeem Akhtar helped in literature review for the report. Mr. Ali Ammad designed layout of the report.

Finally, we must acknowledge the women of the households in the sample districts for sharing their lives and their information and giving life to the survey. We hope very much that our effort will be of use to provide the necessary information to improve the quality of peoples' lives and to provide better reproductive health and family planning services. 


\section{Glossary of Terms}

BHU

CBD

CPR

DHQ hospital

EC

ECPs

FALAHA

FLCFs

FP

IUD

LHWs

$\mathrm{MOH}$

MWRA

NP for FP\&PHC

PHC

PPIU

RHC

THQ hospital

USAID
- Basic Health Unit Community Based Distribution Workers

- Contraceptive Prevalence Rate

- District Headquarters Hospital

- Emergency Contraception

- Emergency Contraceptive Pills

- Family Advancement for Life and Health

- First Level Healthcare Facilities

- Family Planning Intrauterine Device

- Lady Health Workers

- Ministry of Health

- Married Women of Reproductive Age

- National Program for Family Planning and Primary Health Care

- Primary Health Care

Provincial Project Implementation Unit

- Rural Health Centre

- Tehsil Headquarters Hospital

- United States Agency for International Development 


\section{Executive Summary}

\section{Introduction}

Emergency contraception (EC) is contraception administered after unprotected intercourse. EC is the only method women can use to prevent pregnancy after they have had unprotected sexual intercourse, have experienced a contraceptive failure, have remembered too late that they have forgotten to take their birth control pills, or have been forced to have sex against their will. EC is sometimes referred to as "morning-after" or "post-coital" contraception. EC is intended for occasional or emergency use only and not as a regular means of contraception. Formerly, EC was thought to be effective only within 72 hours, but recent studies have confirmed it is effective within 120 hours. Depending on the method used, EC can reduce women's risk of becoming pregnant from a single act of intercourse by 75 to 99 percent.

Emergency contraceptive pills (ECPs) are widely available globally including in Islamic countries such as Bangladesh and Malaysia. In Pakistan, ECPs have been approved by the Government in June 2003 and were registered in 2004. However, they are not widely available, especially through the outlets of the health department. In December 2007, the Population Council organized a five day study tour to Bangladesh to afford an opportunity for officials of both the Ministry of Health $(\mathrm{MOH})$ and Population Welfare to learn from the experience of Bangladesh in introducing ECPs through their National Public Health System. This visit was followed by a National Seminar that was organized in Pakistan by the Population Council's FALAH project with USAID sponsorship. During the seminar, one of the recommendations was that the availability of emergency contraception can be enhanced in Pakistan if it is made available through the outlets of the health system, especially through the network of the community based Lady Health Workers (LHWs).

\section{Training of LHWs}

Training materials that have already been used in Bangladesh were adapted and modified according to the Pakistani scenario. Materials were developed in concurrence with provinces and Training Wing of the National Program for Family Planning and Primary Health Care (NP for FP\&PHC) commonly known as LHW program, MOH.

The training was conducted through the existing training cascade of NP for FP\&PHC in collaboration with Population Council under FALAH Project. Initially district level and subsequently facility level master trainers were developed who imparted training to the LHWs. As a result of these trainings, a total of 2,687 LHWs were trained in the four districts (Table A). Trainings were started in February 2010 and were completed in June 2010 in all the four districts. 
Table A: Number of LHWs trained in emergency contraception by district

$\begin{array}{lr}\text { District } & \text { Number of LHWs trained } \\ \text { DG. Khan } & 1,189 \\ \text { Gawadar } & 112 \\ \text { Mansehra } & 897 \\ \text { Thatta } & 489 \\ \text { Total } & \mathbf{2 , 6 8 7}\end{array}$

\section{Emergency Contraception Survey}

The emergency contraception household survey covers trained LHWs and married women of reproductive age (MWRA), 15-49 years old, living in their catchment areas. The objective is to understand and measure retention of knowledge, attitudes and practices of the trained LHWs and MWRA in their catchment areas regarding the ECPs utility. The survey was divided into two parts, i.e. LHWs and MWRA. The systematic stratified sampling technique was used to select a representative sample of the LHWs. A total of 10 first level healthcare facilities (FLCF) were selected where these LHWs are attached. Subsequently, 5 LHWs were randomly selected per FLCF in each district. A total of 200 LHWs were interviewed during the survey. The random sampling technique was used to select a representative sample of the MWRA. The universe consisted of all the MWRA in the catchment area of each LHW. A total of 10 households were selected per LHW and one MWRA was selected per household. A total of 2,160 women were interviewed in all the four districts (Table B).

Table B: Results of LHWs and MWRA proposed and interviewed in all the four districts

\begin{tabular}{l|r|r|r|r|r} 
Results & DG. Khan & Gawadar & Mansehra & Thatta & Total \\
No. of LHWs interviewed & 50 & 50 & 50 & 50 & 200 \\
\hline No. of LHWs excluded from analysis* & 0 & 4 & 3 & 0 & 7 \\
\hline No. of LHWs included in analysis & $\mathbf{5 0}$ & $\mathbf{4 6}$ & $\mathbf{4 7}$ & $\mathbf{5 0}$ & $\mathbf{1 9 3}$ \\
\hline No. of women interviewed & 545 & 568 & 546 & 501 & $\mathbf{2 , 1 6 0}$ \\
\hline No. of women excluded from analysis** & 0 & 47 & 20 & 0 & 67 \\
\hline No. of women included in analysis & $\mathbf{5 4 5}$ & $\mathbf{5 2 1}$ & $\mathbf{5 2 6}$ & $\mathbf{5 0 1}$ & $\mathbf{2 , 0 9 3}$ \\
\hline $\begin{array}{l}\text { *did not attend ECP training } \\
{ }^{* *} \text { women in the catchment areas of LHWs who did not attend the ECP training }\end{array}$
\end{tabular}

Two questionnaires, one for LHWs and the other for MWRA, were developed for this survey. The questionnaires were designed to contain sufficient information to examine the retention of knowledge and practice regarding the ECP utility in the communities. Female interviewers were hired to interview both female respondents and LHWs. A logistics supervisor was also hired to assist the team. A three day training of all the teams was conducted by the Population Council in Islamabad. During the training, interviewers conducted 2-3 field/mock interviews in order to prepare for the actual interview process. 
Data processing was initiated in the field with the checking of the quality of the questionnaires. On receipt of the questionnaires at the Islamabad office, a team of experienced staff edited the completed questionnaires. After the completion of the editing and coding processes, the questionnaires were handed over to the Data Entry Operators. The data were then analyzed using SPSS for Windows. Fieldwork for all the four districts was carried out between July and August 2011.

\section{Findings}

\section{LHW level}

\section{Background Characteristics and Trainings}

Data obtained from 193 trained LHWs were analyzed. Out of 193 LHWs interviewed, more than half (53 percent) of the LHWs were aged between 25 and 34 years. Seventyfive percent of the LHWs were married at the time of survey. Slightly over half of the LHWs (51 percent) had attained education up to class $10^{\text {th }}$.

All LHWs stated that they had attended at least one training on family planning/ contraceptive technology after completing their basic training. Slightly over two-thirds (68 percent) attended ECP training during the last one year while rest of the LHWs attended ECP training more than 12 months ago. More than half (53 percent) of the LHWs stated that the ECP training was conducted at a Basic Health Unit (BHU).

\section{Retention of Knowledge about ECP use}

A series of questions were asked to assess the retention of knowledge of the LHWs regarding the ECP use. Generally, a substantial majority of the LHWs had a good knowledge of the ECP regarding its suggested dose, effective time duration, side effects etc. A substantial majority of the LHWs (94 percent) stated the correct answer regarding the use of ECPs. Giddiness (81 percent), vomiting (76 percent) and headache (45 percent) were the most commonly reported side effects of the ECP.

\section{Practice of ECP}

When asked about the provision of the ECP to women of their catchment areas, slightly less than three quarters of the LHWs stated that they provided the ECP to all the women who required ECP in their catchment areas. However, 47 percent of the LHWs reported that they did not receive ECP doses from their department on a regular basis. Only 35 percent of the LHWs stated that they kept a record of the ECP clients and 11 percent of the LHWs reported that they referred their clients to the nearest health facilities for ECP during the last month. Nearly three quarters of the LHWs (74 percent) reported that they gave ECP doses to their clients only in the event of emergency, whereas 11 percent reported that they never gave ECP to women of their catchment areas, even at times of emergency, due to non-availability of the ECP supply. However, 6 percent of the LHWs reported that they gave ECP doses beforehand to women of their catchment areas. Eighty seven percent of the LHWs stated that they contacted the ECP clients after giving them ECP doses. Nine percent of the LHWs stated that their clients experienced side 
effects after taking ECP doses during the last month while nearly three fifth (59 percent) of the LHWs stated that they provided treatment for side effects to their clients.

\section{MWRA level}

\section{Background Characteristics}

Slightly over three fifths (62 percent) of the respondents were aged between 25 and 39 years. One third of the respondents (33 percent) stated that they had ever attended the school. Out of those who ever attended the school, half of them (51 percent) had attained education up to the primary level. Fifty-eight percent of the respondents reported that their husbands had attended school. Out of those who reported that their husband had attended the school ever, a quarter ( 24 percent) of the respondents stated that their husbands had attained education up to the primary level. Almost all the respondents reported that LHWs were working in their areas. Sixty nine percent of the respondents reported that LHWs visited their houses every month.

\section{Reproductive History}

A significant majority of the respondents (83 percent) stated of been pregnant ever and 12 percent of the respondents were pregnant at the time of survey. The mean number of children ever born was 3.8 children. More than one third of the respondents (36 percent) had five or more children. Out of those MWRA who wanted more children in the future, 58 percent of the respondents reported to wait for at least two years for the next child.

Nearly one fifth (18 percent) of the respondents were past users. About two fifths (39 percent) of the respondents reported that they were using contraceptives at the time of the interview, i.e. the current users. Hence, the contraceptive prevalence rate (CPR) was 39 percent, a substantially higher than the national figure of 29 percent. Method mix shows that a substantial majority of the current users (84 percent) were modern contraceptive method users. The mostcommon methods used were condoms (24 percent), pills (20 percent), injectables (20 percent) and female sterilization (14 percent).

\section{Knowledge of ECP Use}

A vast majority of the respondents (81 percent) had heard about the ECP, while 71 percent of the respondents reported the purpose of ECP use as to avoid pregnancy after unsafe intercourse. Slightly over half of the respondents (53 percent) stated that the ECP should be used when a woman either forgets to take her regular contraceptives or is late for the next dose. More than one-third of the respondents (37 percent) reported that the ECP should be used within 120 hours after the unsafe intercourse. More than two thirds of the respondents (69 percent) reported the ECP as a safe method and half of the respondents (50 percent) stated that the ECP was not used as a regular contraceptive method. Forty three percent of the respondents said that there were no side effects associated with the ECP. The most common side effects associated with the ECP, reported by the respondents were giddiness (47 percent), vomiting (42 percent), nausea (39 percent) and headache (30 percent). A substantial majority of the respondents (84 percent) reported that the LHW informed them about the ECP. Eight percent of the 
respondents stated that one could easily obtain the ECP in their communities. The most common source for ECP in their communities was reported as the LHWs of their areas (84 percent), followed by medical store (22 percent) and government health facilities (BHU, RHC, DHQ and THQ hospitals) (7 percent).

\section{ECP Users}

Twenty nine percent of the respondents reported ever using ECP. The most common reason stated for ECP use was "rupture of condom during the intercourse" (32 percent), followed by "unsafe intercourse" (27 percent), "forgot to take pills" (20 percent) and "late for next dose of injection" (10 percent). A great majority of the respondents (81 percent) obtained the ECP from the LHW among those who used it last time. A substantial majority of the respondents (82 percent) obtained the ECP free of cost as LHWs provided ECP free of cost. Regarding the effectiveness of ECP, a substantial majority of the respondents (95 percent) stated that it was effective in avoiding pregnancy, when used last time. Slightly over one fifth of the respondents (21 percent) experienced side effects after the use of ECP. The most common side effects experienced were headache and giddiness (52 percent each), followed by vomiting (24 percent), weakness and irregularity in periods (16 percent each). Three fifths of the respondents (60 percent) reported that they contacted the providers for the management of side effects after ECP use. Out of those who contacted, three fifths of the respondents (60 percent) stated contacting the LHWs of their areas. A substantial majority (95 percent) of the respondents would like to advise other women to use ECP in case of emergency. Likewise, slightly over four fifths of the ever users of ECP (81 percent) would like to use ECP (if required) in future.

\section{Conclusions}

To conclude, it is feasible to introduce ECP through LHW program in resource poor communities of Pakistan. There is a high unmet need for ECP in LHW areas, therefore, it is recommended that the ECP program should be scaled up throughout the country in a phased manner. However, it is necessary that LHWs should not face stock outs of ECP, in the absence of the stock unwanted pregnancies cannot be avoided. There is need for supportive monitoring and supervision of the program. In addition, efforts should be made to increase the supply and availability of ECP in the communities. Since the level of knowledge with regard to the use of ECP among MWRA is required to be enhanced, in addition to employing LHWs for this purpose, the use of mass media could also be considered. 


\section{Chapter 1: Introduction}

\section{Background}

Globally, about 210 million women become pregnant each year. However, among them, about 75 million pregnancies (36 percent) are unplanned or unintended (WHO, 2004). Many of these unplanned/unintended pregnancies are not carried to full term, but aborted often in unhygienic conditions. It is estimated that nearly 46 million pregnancies (22 percent of the total pregnancies and 61 percent of the unplanned/unintended pregnancies) are aborted globally. In Pakistan, almost 900,000 abortions take place annually (Population Council, 2004). Thirteen percent of maternal deaths worldwide are due to abortion-related complications and it is one of the leading causes of maternal mortality and morbidity in South Asia. It is also estimated that among the total pregnancies each year in South and South-East Asia, about one-third are unplanned or unintended, i.e. 35 percent in Pakistan, 30 percent in Bangladesh, 21 percent in India and 35 percent in Nepal. The reasons for such a large number of unplanned pregnancies in South and South-East Asia include a low rate of contraceptive use, method failure, and high unmet need for contraceptives (Adhikari, 2009). In addition, more than 20 million women worldwide experience ill health as a result of pregnancy every year (WHO/SEARO, 2001). It is estimated that between 8 and 30 million pregnancies every year result from contraceptive failure either due to inconsistent or incorrect use of contraceptive methods or failure of the method itself (Segal and LaGuardia, 1990). Moreover, according to an estimate, the increase in total population of South and South-East Asia each year could be reduced by one-third if all unplanned or unintended births were avoided.

Pakistan, with an estimated population of nearly 175 million, is the sixth most populous country in the world. With a growth rate of 2 percent, the doubling time is 35 years. The total fertility rate is around 4.1 and contraceptive prevalence rate (CPR) is at 30 percent. There is high unmet need for family planning at 25 percent (NIPS and Macro, 2008). Pakistan was among the first countries in the world to implement a national family planning program; however the current situation suggests that there are major barriers to adopting family planning even among those who already wish to delay or limit childbearing.

Abortion is not legally allowed in Pakistan. Nevertheless, induced abortion is practiced as a method to regulate fertility in Pakistan and it does stand out as one of the deliberate marital fertility control factors. It is hard to gather accurate information on the prevalence of induced abortion in Pakistan. However, the available data do suggest that almost 20 percent pregnancies were unwanted in 1990-91, which increased to 28 percent in 1996-97 and to 36 percent in 2003. The unwanted pregnancies dropped to 24 percent of all pregnancies in 2006-07 (Khan, 2010). This trend is consistent with the earlier 
findings that with declining fertility, the proportion of unwanted births first rises and then falls (Bongaarts, 1997). High unmet need for contraception (currently 25-30 percent of all married women), and the proportion of unwanted pregnancies reflect the potential risk of induced abortion (Sathar, 2007). Further, a study conducted in 2002-03 by Population Council found that there was one abortion for every five live births, implying that every Pakistani woman on an average has one abortion during her lifetime. The study concludes that induced abortion is a significant means of fertility control in Pakistan (Population Council, 2004). An estimated 197,000 women are treated each year for complications resulting from unsafe induced abortions in public health facilities and private teaching hospitals. Clearly morbidity resulting from unsafe abortion has a substantial impact on women's health and results in significant burden on the health care system.

In recent years, emphasis is being placed upon repositioning family planning as a major health intervention and to encourage birth spacing as an integral component of reproductive health. Women, who have too close and too many births, frequently have higher chances of pre-term delivery with low-birth weight children. Studies have consistently demonstrated the health benefits of birth spacing for the family with gaps of at least 24 months between children.

Pakistan has lagged behind regional countries in meeting the challenge of lowering the rate of growth of burgeoning population due to a variety of reasons. Most common reasons are lack of access to quality family planning services in both public and private sectors, fear of side effects of contraceptive and due to this fear they are either not using contraceptives resulting in an unmet need for family planning or resorting to inducing abortions for unwanted pregnancies, or else are switching contraceptive methods quite frequently. Method failure due to improper use has also resulted in discontinuation of contraceptive use in many instances. If unmet need could be met, the fertility rate in Pakistan could be brought down significantly to the replacement level.

Based on the above stated situation in order to reduce the number of unwanted and unplanned pregnancies it is important that the efficacy of barrier and hormonal contraceptives is enhanced by the availability of a method that provides backup support to these methods. Emergency contraception is one way of doing so (Piaggio et al., 1999).

\section{Emergency Contraception}

Emergency contraception (EC) is contraception administered after unprotected intercourse. EC is the only method women can use to prevent pregnancy after they have had unprotected sexual intercourse, have experienced a contraceptive failure, have remembered too late that they have forgotten to take their birth control pills, or have been forced to have sex against their will. EC is sometimes referred to as "morning-after" or "post-coital" contraception. EC is intended for occasional or emergency use only and not as a regular means of contraception. Formerly, EC was thought to be effective only 
within 72 hours, but recent studies have confirmed it is effective for up to 120 hours (International Consortium for Emergency Contraception, 2004, Schwarz et al., 2007). EC methods include taking special doses of ordinary birth control pills as well as inserting an intrauterine device (IUD). Depending on the method used, EC can reduce women's risk of becoming pregnant from a single act of intercourse by between 75 and 99 percent (Consortium for Emergency Contraception, 2000).

Emergency contraceptive pills (ECPs) are widely available globally including Islamic countries such as Bangladesh and Malaysia. In Pakistan, ECPs have been approved by the Government in June 2003 and were registered in 2004. However, they are not widely available, particularly through the outlets of the health department. In December 2007, the Population Council organized a five day study tour to Bangladesh to afford an opportunity for officials of both the Ministry of Health $(\mathrm{MOH})$ and Population Welfare to learn from the experience of Bangladesh in introducing ECPs through their National Public Health System. This visit was followed by a National Seminar that was organized in Pakistan by the Population Council's FALAH project with USAID sponsorship. The seminar brought together national and international experts, religious scholars, researchers along with government policy makers who discussed the possibility of expanding the provision of ECP through both the static and community based providers of the Ministry of Health. Both the Ministers of Population Welfare and Health endorsed the idea of making ECPs widely available so as to increase the effectiveness of temporary contraceptive methods.

During the seminar, one of the recommendations was that the availability of emergency contraception can be enhanced in Pakistan if it is made available through the outlets of the health system especially through the network of the community based Lady Health Workers (LHWs). Evidence from regional countries that was shared at the seminar showed that all categories of health providers including the outreach workers can be effectively trained to provide emergency contraception pills in order to reduce the rate of unwanted pregnancies, induced abortions and increase contraceptive choices as well as provide backup support for existing methods. Evidence from Bangladesh showed that retention of ECP knowledge in all levels of providers was high even 4 months after training. Result from operations research in Bangladesh also shows a high acceptability of EC with the eligible clients. This shows that training could be successfully imparted to all categories of providers including grassroots and CBD workers (Khan et al., 2004). Evidence from India also shows that paramedics can be trained in the provision of ECP. After training, both the doctors and paramedics achieved the same level of expertise in provision of ECP (Sebastian et al., 2005). 


\section{Intervention - Training of LHWs}

\section{Development of Training Material}

Training materials that have already been used in Bangladesh were adapted and modified according to Pakistani scenario. Materials were developed in concurrence with provinces and training wing of the National Program for Family Planning and Primary Health Care (NP for FP\&PHC) commonly known as LHW program, MOH. Pre-test and post test was held during the trainings. Following materials were used:

- Trainer's Manual: was developed and used for providing training to the master and facility trainers;

- Trainees Manual: was developed for each LHW in the project districts (both in Urdu \& Sindhi languages).

\section{Training Process}

The training was conducted through the existing training cascade of NP for FP\&PHC $(\mathrm{MOH})$ in collaboration with Population Council under FALAH Project. Initially the capacity of district level master trainers and then facility level trainers was developed who imparted training to the LHWs. One national level workshop was also conducted for training the master trainers who, later on, provided training to the district trainers. The facility based trainers imparted two day training to the LHWs. As a result of these trainings, a total of 2,687 LHWs were trained in the four districts (Table 1.1). All the trainings were started in February 2010 and were completed in June 2010.

\section{Training Cascade of National Program}

\begin{tabular}{|c|c|}
\hline National level workshop & District Master T \\
\hline District level workshop & Facility Trainers \\
\hline Facility level workshop & LHWs \\
\hline
\end{tabular}


Table 1.1: Number of LHWs trained in emergency contraception by district

\begin{tabular}{l|r} 
District & Number of LHWs trained \\
DG. Khan & 1,189 \\
\hline Gawadar & 112 \\
\hline Mansehra & 897 \\
\hline Thatta & 489 \\
Total & $\mathbf{2 , 6 8 7}$
\end{tabular}

\section{Supply of ECPs}

The responsibility of providing ECP was taken by UNFPA during the National Seminar on ECP conducted by Population Council in 2008.

\section{Emergency Contraception Survey}

A survey was conducted to review the retention of knowledge and practice of the trained LHWs and married women of reproductive age (MWRA) in their catchment areas in all the four districts.

\section{Methodology}

The emergency contraception household survey covers the trained LHWs and MWRA (15-49 years old) living in their catchment areas. The objective is to understand and measure the retention of knowledge, attitudes and practices of the trained LHWs and MWRA in their catchment areas regarding the ECP.

\section{Sample Design and Size}

The survey was divided into two parts, i.e. LHWs and MWRA.

\section{Selection of LHWs}

The systematic stratified sampling technique was used to select a representative sample of the trained LHWs. The universe consisted of all the trained LHWs in all the four districts - DG. Khan, Gawadar, Mansehra and Thatta. First, a total of 10 first level healthcare facilities (FLCF), including Basic Health Unit and Rural Health Centers, were selected randomly in each district. Afterward 5 LHWs were randomly selected per FLCF. Hence, a total of 200 LHWs were selected and interviewed during the survey in all the four districts. However, data of seven LHWs were excluded from the analysis as those LHWs did not attend the ECP training under the FALAH project. Therefore, data of 193 LHWs were analyzed and presented in this report.

\section{Selection of MWRA}

The simple random sampling technique was used to select a representative sample of the MWRA. The universe consisted of all the MWRA in the catchment area of the selected LHW in each district. A total of 10 households were selected per LHW and one 
MWRA was selected per household. Hence, a total of 2,160 women were selected and interviewed in all the four districts. However, we have excluded the data of 67 women as their LHWs were not trained in the ECP under FALAH project. Hence, data of 2,093 women were analyzed and reported in this report.

Table 1.2: Results of LHWs and MWRA proposed and interviewed in all the four districts

\begin{tabular}{|c|c|c|c|c|c|}
\hline Results & DG. Khan & Gawadar & Mansehra & Thatta & Total \\
\hline No. of LHWs interviewed & 50 & 50 & 50 & 50 & 200 \\
\hline $\begin{array}{l}\text { No. of LHWs excluded from } \\
\text { analysis* }\end{array}$ & 0 & 4 & 3 & 0 & 7 \\
\hline $\begin{array}{l}\text { No. of LHWs included in } \\
\text { analysis }\end{array}$ & 50 & 46 & 47 & 50 & 193 \\
\hline No. of women interviewed & 545 & 568 & 546 & 501 & 2,160 \\
\hline $\begin{array}{l}\text { No. of women excluded } \\
\text { from analysis** }\end{array}$ & 0 & 47 & 20 & 0 & 67 \\
\hline $\begin{array}{l}\text { No. of women included in } \\
\text { analysis }\end{array}$ & 545 & 521 & 526 & 501 & 2,093 \\
\hline
\end{tabular}

\section{Questionnaire Design}

Two questionnaires, one for the assessment of LHWs and the other for MWRA, were developed for this survey. The questionnaires contained sufficient information to examine the retention of knowledge and practice of the LHWs and MWRA regarding the emergency contraception in the communities after the provision of trainings and supplies of ECP.

The questionnaires were pre-tested in both urban and rural areas of Islamabad. The main objective of the pre-testing was to examine the suitability and effectiveness of questions in eliciting adequate responses, to check if the interviewers or respondents would face any language problems and to determine the approximate time required to complete one questionnaire. After making all the revisions on the basis of the pre-test, the questionnaires were finalized.

\section{Hiring of Interviewers and Supervisors}

Since the respondents in the survey were currently married women and the LHWs of their areas, female interviewers were hired to interview them. Two interviewers per district were hired locally and a logistics supervisor (male member) was also hired to assist the team.

\section{Training of Interviewers and Supervisors}

In order to ensure that the training provided to the interviewers was of high quality, and that interviewers understood the definitions and concepts underlying the language of the questions, a three day training of all the teams was conducted by the Population 
Council in Islamabad. During the training, interviewers also conducted 2-3 mock interviews of MWRA in order to prepare for the actual interview process.

\section{Quality Assurance}

To ensure the quality of the data, Population Council staff monitored the fieldwork by accompanying the field teams. While supervising the fieldwork, Population Council supervisory staff members were also available to provide on-the-spot guidance to interviewers in the event that any part of the questionnaire was unclear to them. This ensured the completeness and accuracy of each questionnaire. Moreover, the Population Council staff often conducted validation of the completed interviews in the communities.

\section{Data Entry and Edit Procedures}

Data processing was initiated in the field with the checking of the completeness of the questionnaires. On receipt of the questionnaires at the Islamabad office, a team of experienced staff edited the filled-in questionnaires. After the completion of the editing and coding process, the questionnaires were handed over to the data entry operators. The data were then analyzed using SPSS software for Windows.

\section{Fieldwork}

Fieldwork for all the four districts was carried out between July and August 2011. 



\section{Chapter 2: Major Findings at LHW Level}

This section presents the overall findings of the survey at LHW level of all the four districts. The section depicts the background characteristics of the LHWs, followed by their training status, retention of knowledge about ECP, and their current practices regarding the ECP. The district wise tables are given in Annexure 2.

\section{Background Characteristics}

\section{Age and Marital Status}

LHWs should be aged between 20 and 50 at the time of recruitment, though 18 and 19 year olds may be admitted if married. Figure 2.1, shows that LHWs are predominantly young women; more than half (53 percent) of the LHWs were aged between 25 and 34 years, compared to the national figure of 66 percent reported by the recent third party evaluation of LHW program (Oxford Policy Management 2009). Figure 2.2 shows that majority of LHWs are currently married, as preferred by the program, although one fifth of the LHWs (20 percent) have never been married, whereas nationally over a quarter have never been married (Oxford Policy Management 2009).

Figure 2.1: Percentage of LHWs by age groups $(\mathrm{N}=193)$

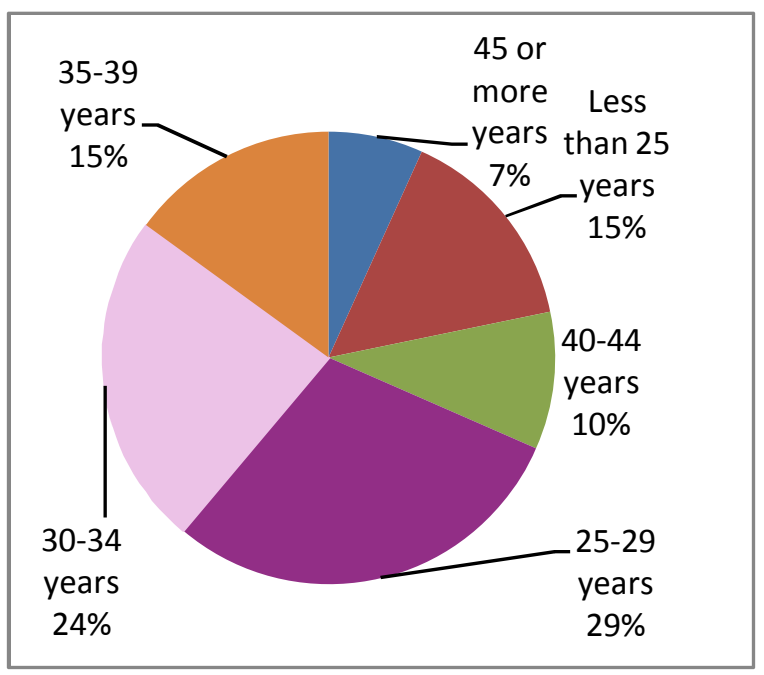

Figure 2.2: Percentage of LHWs by their marital status $(\mathrm{N}=193)$

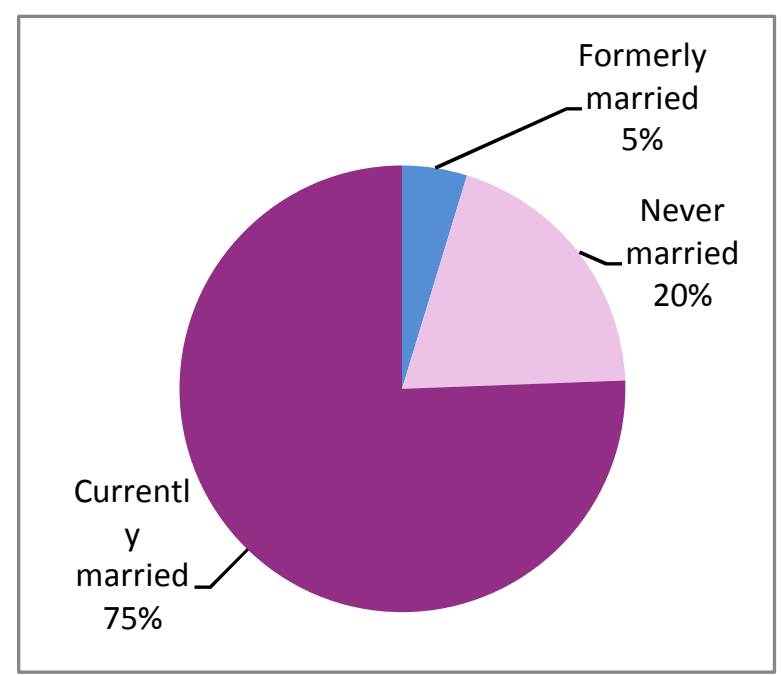




\section{Education and Work Experience}

LHWs should be educated until at least the eighth grade, though it is preferable for them to be matriculated/tenth grade. Based on LHW self-reporting, as shown in Figure 2.3, 2 percent had received up to primary education, comparable to national level figure of less than 1 percent (Oxford Policy Management 2009). Likewise, 23 percent reported receiving fewer than the ten years (till middle class), which is slightly less than the national figure of 36 percent (Oxford Policy Management 2009).

LHW program was launched in 1994 by the Ministry of Health, Government of Pakistan. It soon employed only female community health workers - Lady Health Workers (LHWs). Figure 2.4 shows about one third of the LHWs (34 percent) were working as LHW for the last 11 years or more.

Figure 2.3: Percentage of LHWs by their education level $(\mathrm{N}=193)$

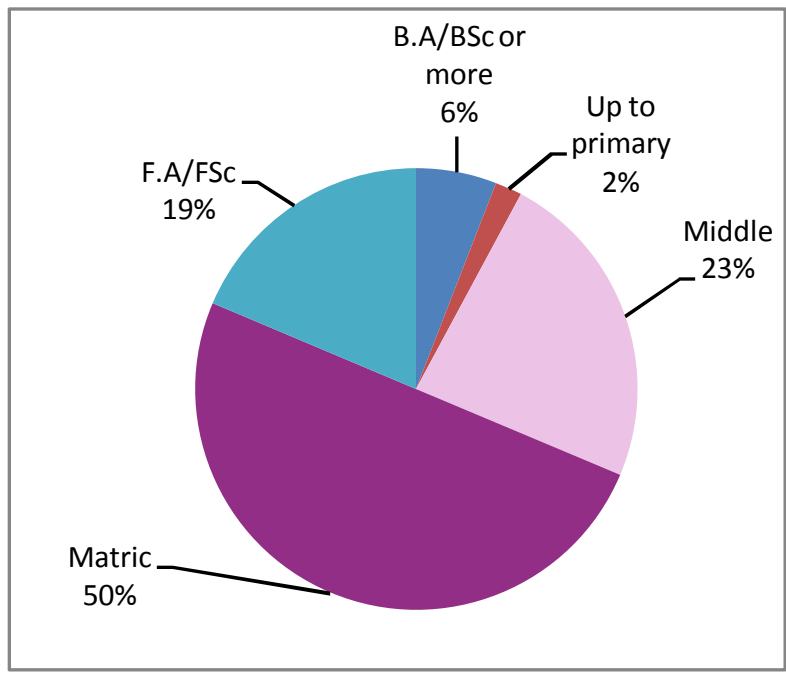

Figure 2.4: Percentage of LHWs by their work experience $(\mathrm{N}=193)$

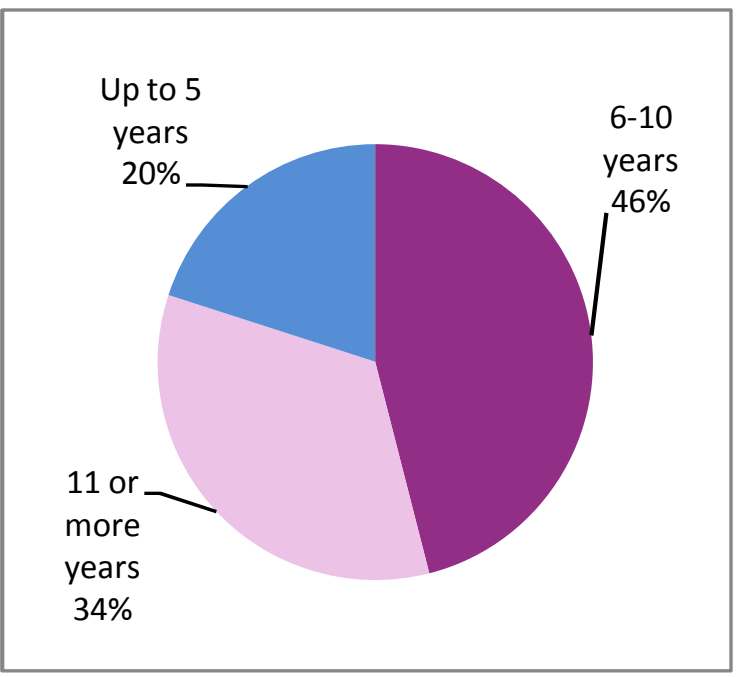

\section{ECP Trainings}

Soon after the hiring of LHWs, a basic training is provided by the NP for FP \& PHC to all the employed LHWs. The basic training takes 15 months, including 3 months of classroom training and 12 months of field training (Nisar, 2008). In this survey, all the interviewed LHWs stated that they had attended at least one additional family planning training after completing their basic training. Further, when asked about the additional trainings, 98 percent of the LHWs reported that they had attended Client Centered Approach (CCA) training under the FALAH project. About two thirds (67 percent) attended the CCA training during the last one year. Likewise, all the LHWs reported that they had attended the ECP training. Slightly over two thirds (68 percent) attended the ECP training during the last one year. More than half (53 percent) of the LHWs stated that the ECP training was conducted at Basic Health Unit (BHU) and about 74 percent of the LHWs reported that they were invited by their Lady Health Supervisors 
(LHSs). Regarding the provision of education materials at the end of the training, 89 percent of the LHWs reported that 'information/ ranking card on $\mathrm{ECP}^{\prime}$ were provided to them while 73 percent and 84 percent of the LHWs stated that 'participant manual' and 'booklet on ECP refresher course' were provided to them, respectively. About 89 percent of the LHWs received payments at the end of the training.

\section{Retention of Knowledge about ECP}

\section{Use of ECP}

When asked, when to use ECP, a substantial majority of the LHWs (94 percent) stated the correct answer, i.e. to avoid pregnancy after unsafe intercourse.

Regarding the common conditions in which ECP should be used, Figure 2.5 shows that about four fifths (80 percent) of the LHWs reported that the ECPs should be used after accidental rupture of condom

Figure 2.5: Percentage of LHWs reported the use during the intercourse, while 78 percent stated that 'when a woman who is using contraceptive pills, but forgets to take it' she should use ECP after unsafe intercourse. Sixty percent of the LHWs reported that a woman should use ECP when she is on injectable contraceptives but late to take next dose after unsafe intercourse.

Figure 2.6: Percentage of LHWs reported the common conditions in which ECP should be used $(\mathrm{N}=193)$

\section{of ECPs $(N=193)$}

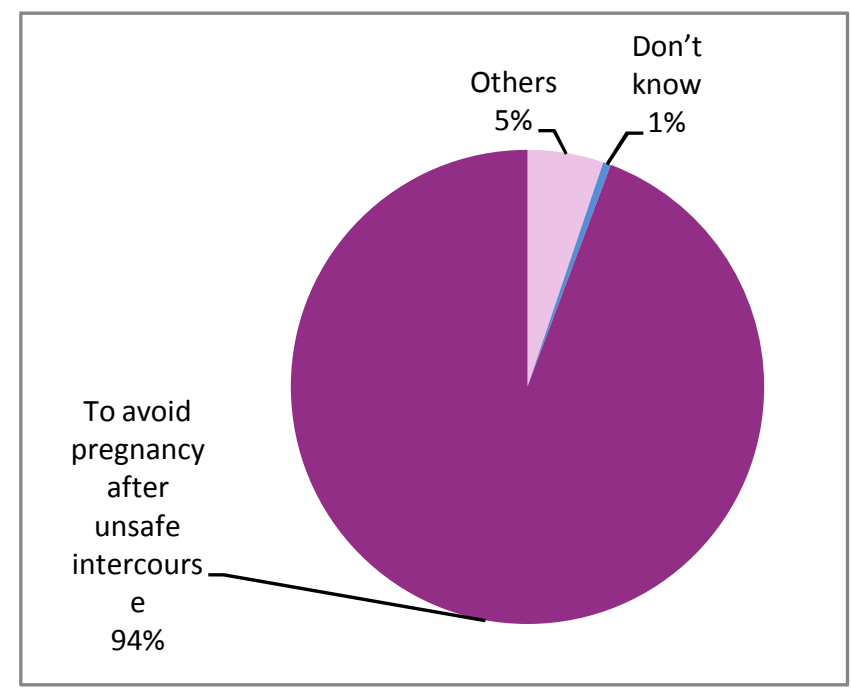

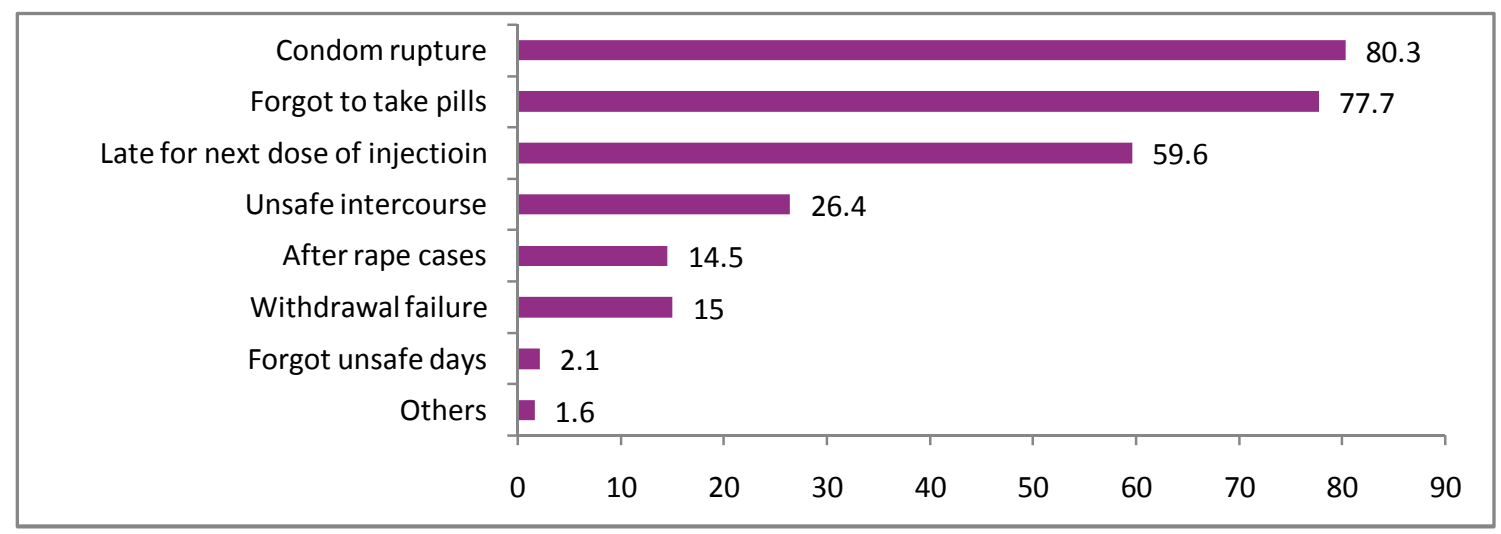




\section{Information about ECP Use}

A series of questions were asked to assess the retention of knowledge of the LHWs regarding the ECP use. Generally, a substantial majority of the LHWs had good knowledge of the ECP regarding its dose, effective time duration, side effects etc.

When asked about the effective duration/ time period of the ECP to be used as shown in Figure 2.7, more than half of the LHWs (53 percent) stated the correct answer, i.e. up to 120 hours after unsafe intercourse. Moreover, a great majority of the LHWs (94 percent) reported correct dosage of ECP, i.e. 2 tablets at once.

When asked about the use of ECP as a regular contraceptive method, 94 percent of the LHWs reported the correct answer, i.e. ECP cannot be used as a regular contraceptive method. Further, when asked about the side effects associated with ECP, almost three fifths of the LHWs (58 percent) stated that there were no side effects associated with the use of ECP. About 42 percent of the LHWs who stated the presence of side effects mentioned giddiness ( 81 percent), vomiting (76 percent) and headache (45 percent) (data not shown).

A great majority of the LHWs (96 percent) considered the ECP as a safe contraceptive to be used as emergency contraception. Eighty eight percent of the LWHs reported that the pregnancy test should be advised to a woman if her regular menstrual cycle has been delayed after taking the ECP. Ninety-five percent of the LHWs stated that ECP was not a type of abortion while 91 percent reported that a woman should not take more than two doses of ECP in a month. Seventy two percent of the LHWs reported that ECP had no impact on the client's/user's menstrual cycle. When asked if a woman is not sure about her pregnancy status and wanted to use ECPs to avoid pregnancy, can she use ECP, 88 percent of LHWs responded with the correct answer, i.e. a woman cannot use the ECP. Further, 62 percent of the LHWs stated that a lactating mother can use ECP, if she requires.

Figure 2.7: Percentage of LHWs reported the correct information about ECP use $(\mathrm{N}=193)$

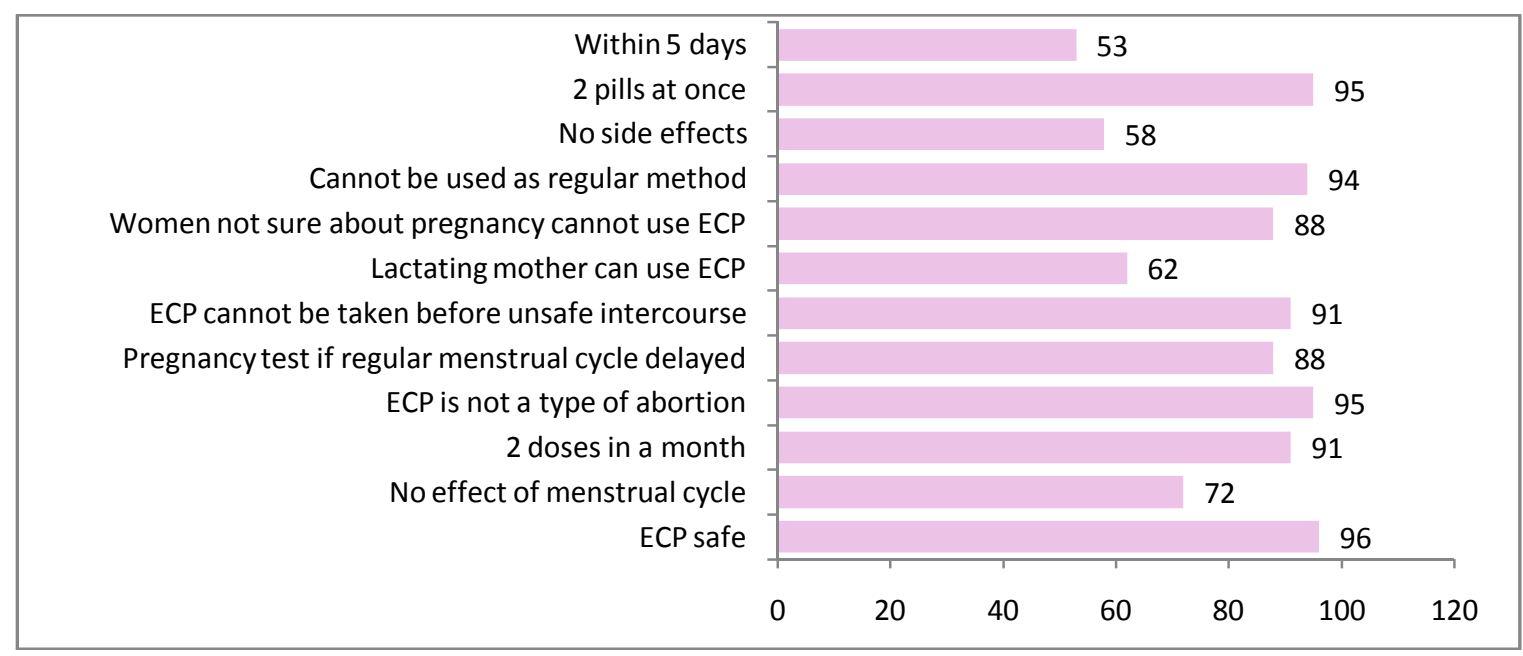




\section{Practice of ECP Utility}

\section{Provision and Supply of ECP}

When asked about the provision of ECP doses to the MWRA of their catchment areas, slightly less than three quarters of the LHWs stated that they provided the ECP doses to all the MWRA who required them in their catchment areas. Likewise, those LHW who provided ECP doses to their clients, when asked about the supply of ECP doses from their organization, 47 percent of the LHWs reported that they did not receive ECP doses from

their Department on a regular basis. Figure 2.8 Furthermore, when asked about how many doses they received in the last month before the current survey, about three quarters of the LHWs (73 percent, $\mathrm{n}=103$ ) reported that they did not receive any doses of ECP from their organization during the last month before the survey.

\section{Record Keeping of ECP Clients}

When asked about the record keeping

of ECP clients, figure 2.9 shows that only 35 percent of the LHWs stated that they kept the record of ECP clients. However, out of those 35 percent, only half of them (52 percent) were able to show the list of ECP clients. Amongst those who reported maintaining the record of ECP clients, the average number of ECP users per LHW was 1.13 during the last month before the survey.
Figure 2.8: Percentage of LHWs who provided ECP doses to women $(N=193)$ and who received ECP supply from organization regularly $(N=141)$

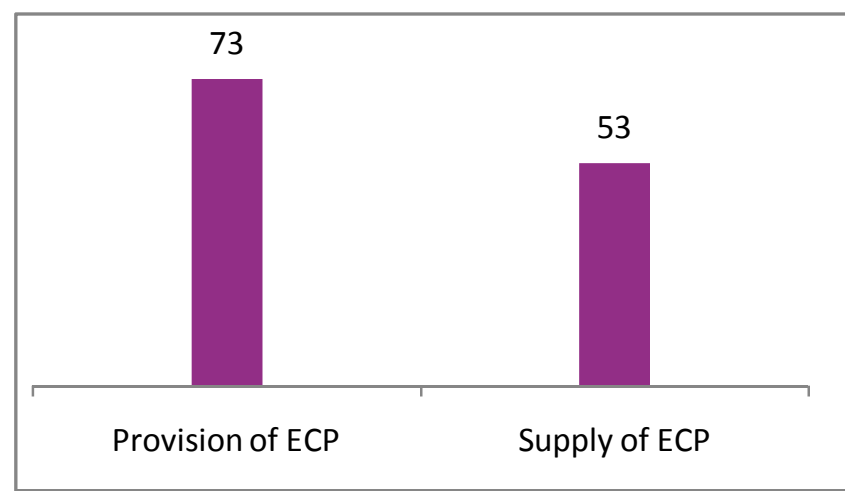

Figure 2.9: Percentage of LHWs who kept ECP client record $(\mathrm{N}=181)$ and who showed list of ECP clients $(\mathrm{N}=64)$

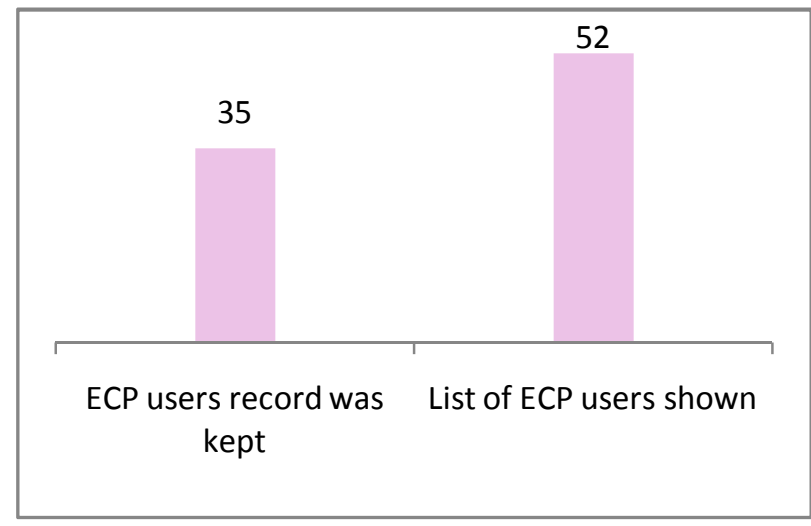

Figure 2.10: Percentage of LHWs who made referral of women to health facilities for ECP (N $=181$ ) and who showed list of referral women $(\mathrm{N}=19)$

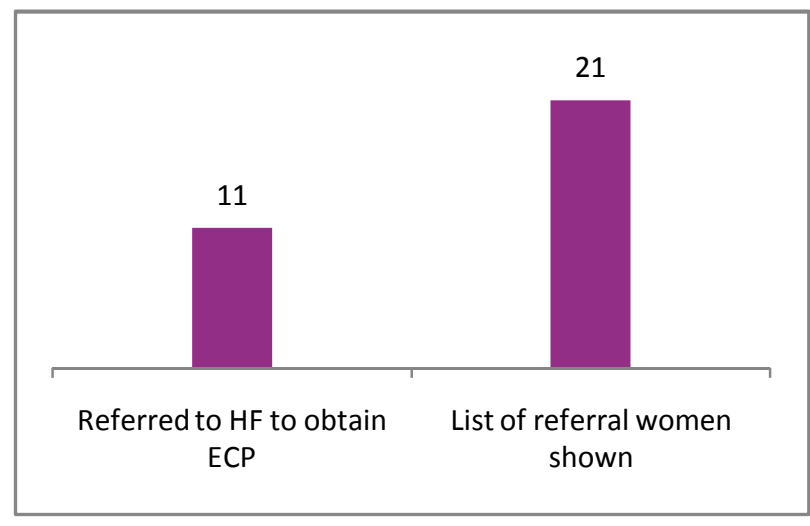




\section{Referred to Health Facility for ECP doses}

When asked about the referral of MWRA of their catchment areas to nearest health facilities to obtain ECP doses during the last month before the survey, as shown in figure 2.10, 11 percent of the LHWs reported that they referred MWRA to the nearest health facility for ECP. Amongst those who referred the MWRA to nearest health facility, the average number of women referred per LHW was 1.6 during the last month before the survey. Out of those who made referrals, only one fifth (21 percent) of the LHWs were able to show the list of women referred.

\section{Giving ECP Doses}

Figure 2.11 shows that nearly three quarters of the LHWs (74 percent) reported that they gave ECP doses to their clients only in the event of emergency, i.e. after unsafe intercourse, whereas 11 percent reported that they never gave ECP to women of their catchment areas, even when they required it, due to non-availability of the ECP doses. However, 6 percent of the LHWs reported that they gave ECP

Figure 2.11: Percentage of LHWs by giving ECP to women $(\mathrm{N}=181)$

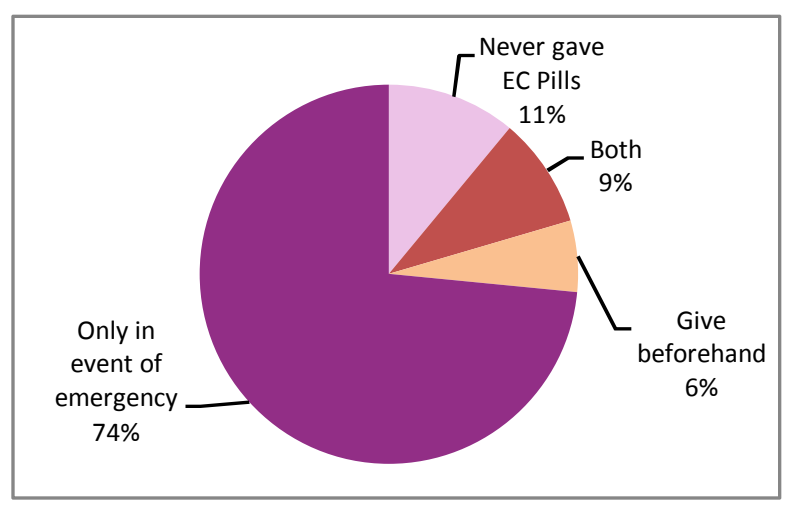
doses beforehand to women in their catchment areas.

\section{Follow up of ECP Clients}

Figure 2.12 shows that eighty seven percent of the LHWs stated that they contacted their ECP clients after giving them ECP doses. When asked about the side effects associated with the ECP, 9 percent of the LHWs stated that their clients experienced side effects after taking ECP doses during the last month before the survey. Further, out of those who reported side effects, nearly three fifths (59 percent) of the LHWs stated that they provided treatment for side effects to their clients. When asked about the referral of clients to the health facilities for the management of side effects due to the use of ECP, 35 percent of the LHWs reported that they referred their clients to the nearest health facilities for management. 
Figure2.12: Percentage of LHWs who contacted the ECP clients and managed side effects $(\mathrm{N}=$ 181)

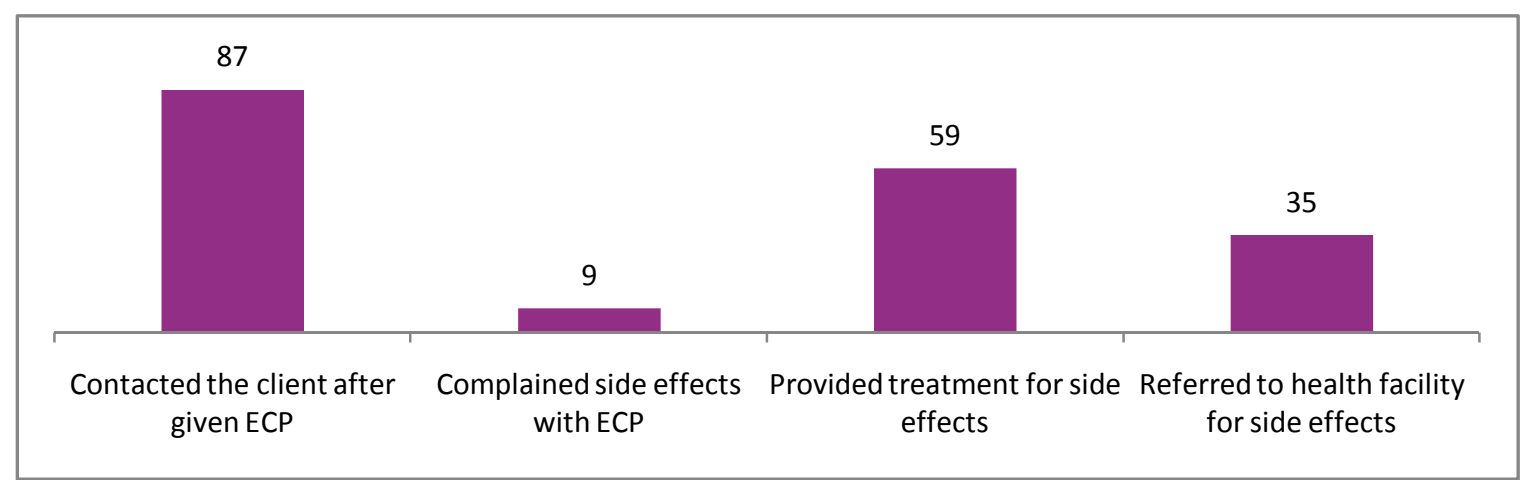





\section{Chapter 3: Major Findings at Married Women of Reproductive Age Level}

This section explains the overall findings of the survey at the MWRA level of all the four districts. The section presents the background characteristics of the MWRA, followed by their reproductive history, their current knowledge about ECP, and practice and perception of ECP users.

\section{Respondent Characteristics}

\section{Age and Education}

Slightly over three fifths (62 percent) of the respondents were aged between 25 and 39 years, while one fifth (20 percent) of the respondents were younger than 25 years. Seventeen percent of the respondents were aged 40 and above.

Table 3.1: Age distribution of MWRA

\begin{tabular}{l|r|r} 
Age groups & Percentage & N \\
$15-19$ years & 3.4 & 71 \\
\hline $20-24$ years & 17.0 & 356 \\
\hline $25-29$ years & 24.1 & 504 \\
\hline $30-34$ years & 20.0 & 418 \\
\hline $35-39$ years & 18.0 & 377 \\
\hline $40-44$ years & 12.7 & 265 \\
\hline 45 - 49 years & 4.7 & 98 \\
\hline No information & 0.2 & 4 \\
Total & $\mathbf{1 0 0 . 0}$ & $\mathbf{2 0 9 3}$
\end{tabular}

One third of the respondents (33 percent) had ever attended school. Out of those who ever attended school, slightly over half (51 percent) had attained education up to the primary level, whereas more than one-third of the respondents (37 percent) had attained education till class $10^{\text {th }}$ and above. 
Figure 3.1: Percentage of MWRA by ever attended school $(\mathrm{N}=2093)$

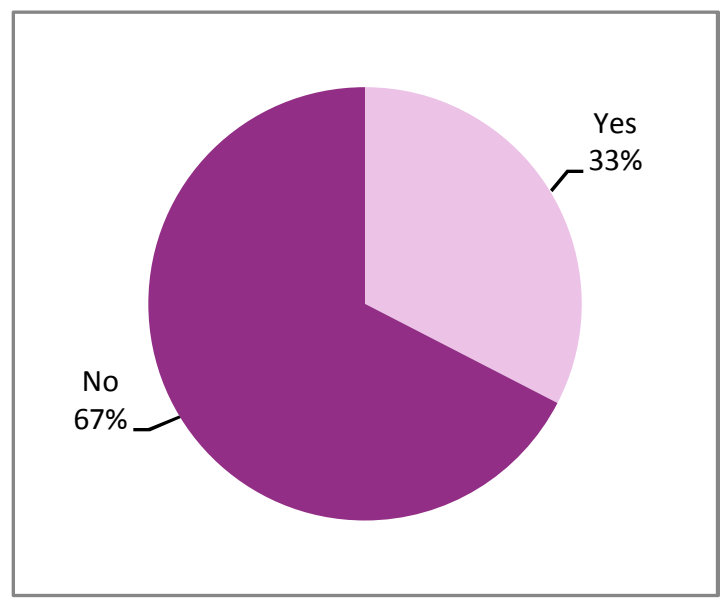

Figure 3.2: Percentage of MWRA by highest level of education attained $(\mathrm{N}=683)$

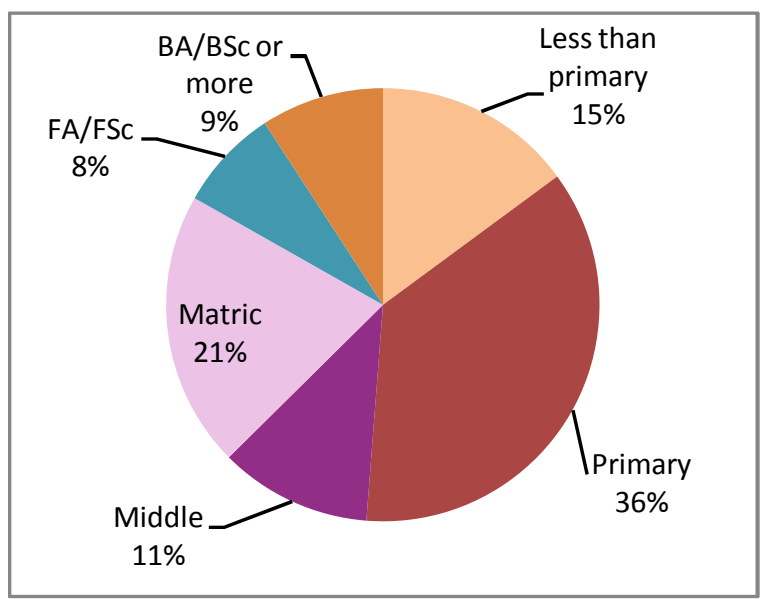

When asked about the educational status of their husbands, 58 percent of the respondents reported that their husbands had attended school. Out of those who reported that their husband attended school, a quarter (24 percent) of the respondents stated that their husbands had attained education up to the primary level, whereas slightly over three fifths of the respondents (62 percent) reported that their husbands had attained education till class $10^{\text {th }}$ and above.

Figure 3.3: Percentage of MWRA whose husbands attended school $(\mathrm{N}=2093)$

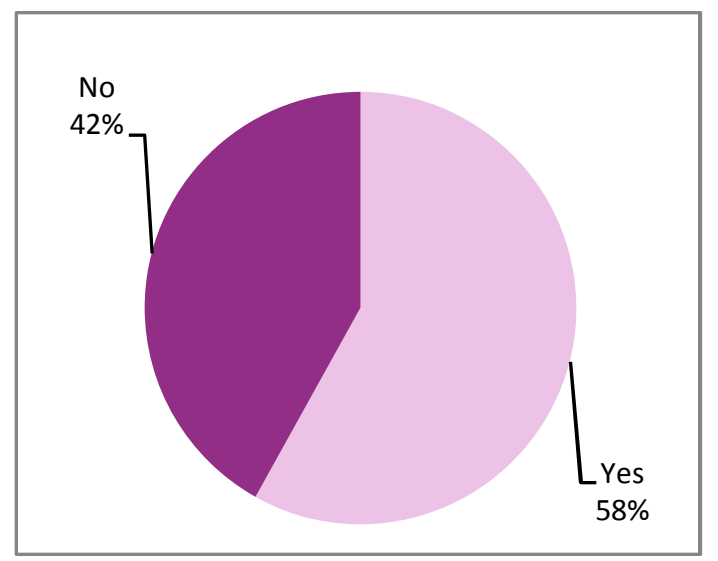

Figure 3.4: Percentage of MWRA by level of education attained by their husbands $(\mathrm{N}=1217)$

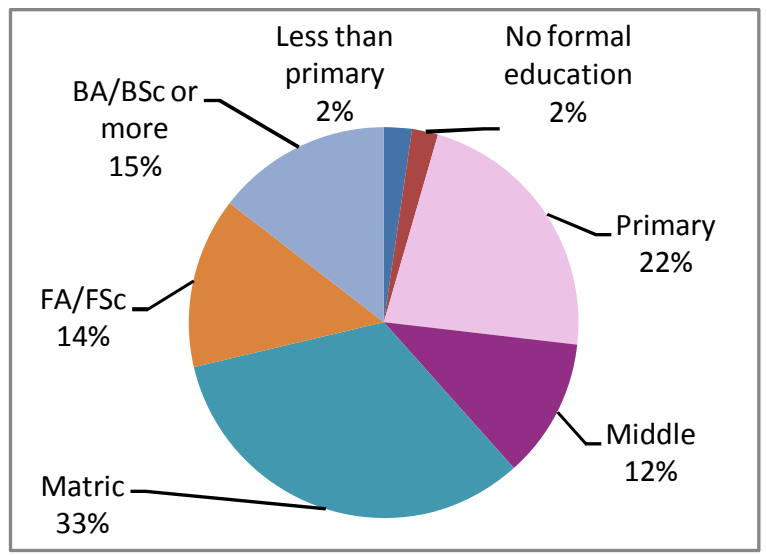




\section{LHW Availability in Community}

When asked about the presence of LHWs in their communities, almost all (99.4 percent) the respondents reported the presence of LHWs in their areas. A great majority of the respondents (94 percent) even knew the name of their LHWs.

Sixty nine percent of the respondents reported that LHWs visited their homes every month, while only 3 percent of the respondents reported that the LHWs of their area never visited theirhomes. One fifth of the respondents (20 percent) stated that LHWs visited their homes every fortnight.

\section{Reproductive History}

\section{Ever Pregnant}

A substantial majority of the respondents (83 percent) stated being pregnant at some point and 12 percent of the respondents were pregnant at the time of survey. Less than 6 percent of the women had never been pregnant.

\section{Number of Children}

The mean number of children ever born was 3.8 children in all the MWRA. Table 4 shows that 91 percent of all the respondents had already given birth to at least one child. More than one third of the respondents (36 percent) had five or more children. The mean number of sons was 1.9, whereas the mean number of daughters was 1.8.

Table 4: Distribution of MWRA by number of children and mean children $(N=2093)$

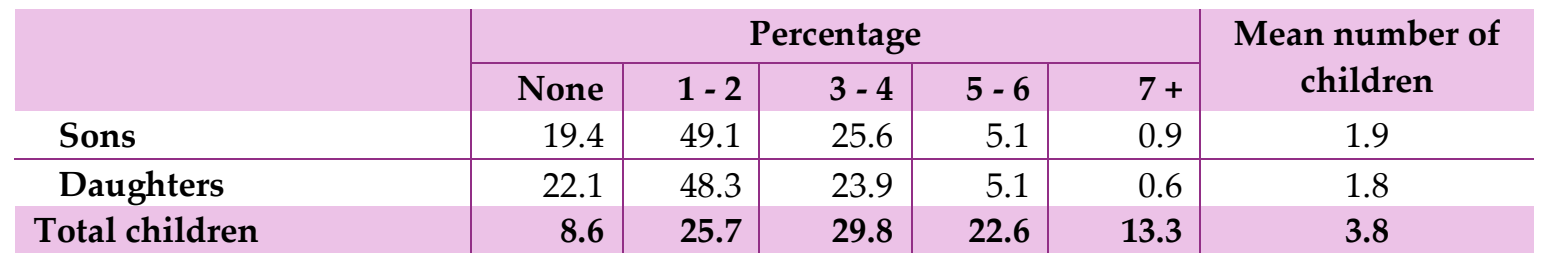
visits of LHWs $(\mathrm{N}=\mathbf{2 0 8 1})$

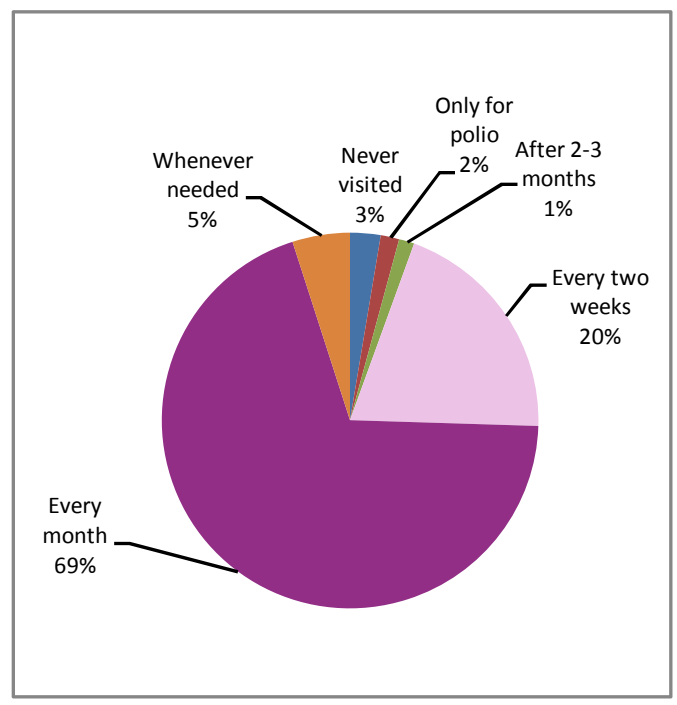

Figure 3.6: Percentage of MWRA by ever being pregnant $(\mathrm{N}=2093)$

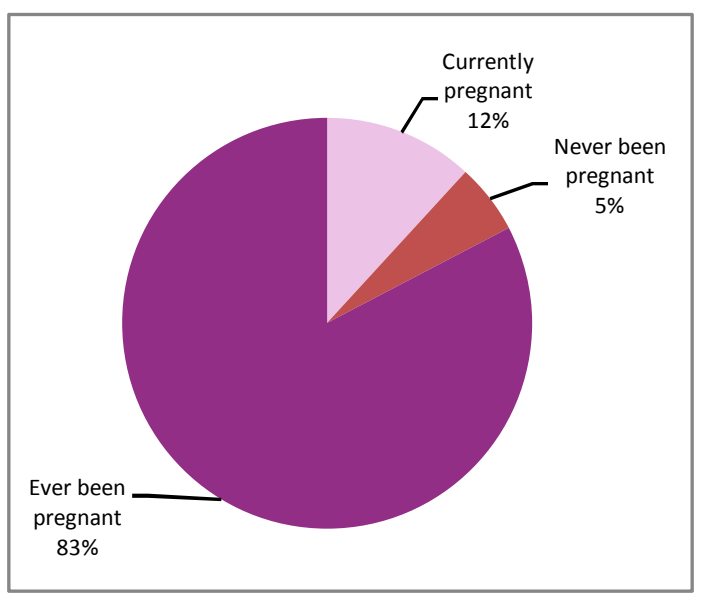

Figure 3.5: Percentage of MWRA by home 


\section{Age of the Youngest Child}

More than two fifths of the respondents (43 percent) had their youngest child of up to 2 years of age at the time of interview. Nearly one fifth of the respondents (19 percent) had the youngest child aged 5 years and above. About 9 percent of the respondents had no child at the time of survey.

\section{Desire for More Children}

Forty three percent of the respondents stated that they did not want more children at all, while 4 percent were unsure. Slightly over half (53 percent) of the respondents wanted more children in future. Out of those MWRA who wanted more children in future, 30 percent stated that they wanted the next child as soon as possible, whereas half of the respondents wanted to wait for up to 3 years for the next child.

Figure 3.8: Percentage of MWRA by the time period to wait before the birth of next child $(\mathrm{N}=1104)$

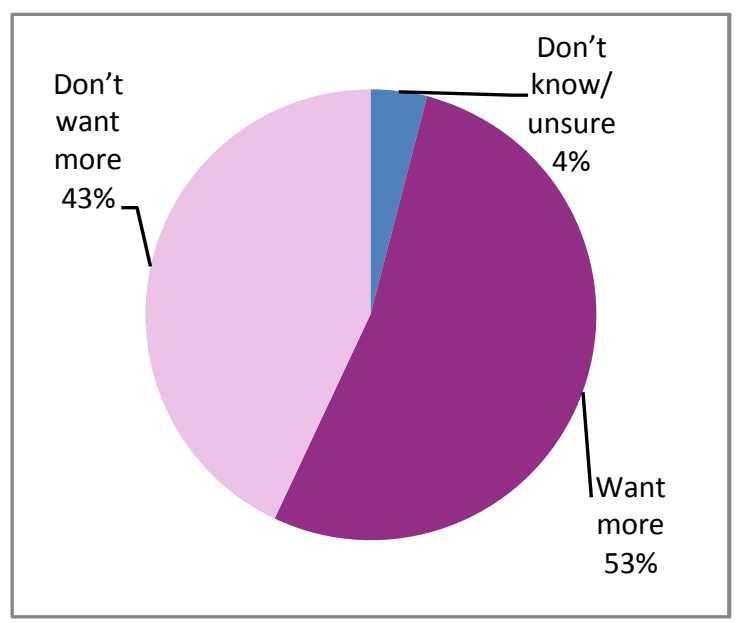

Figure 3.7: Percentage of MWRA by the age of the youngest child $(N=2093)$

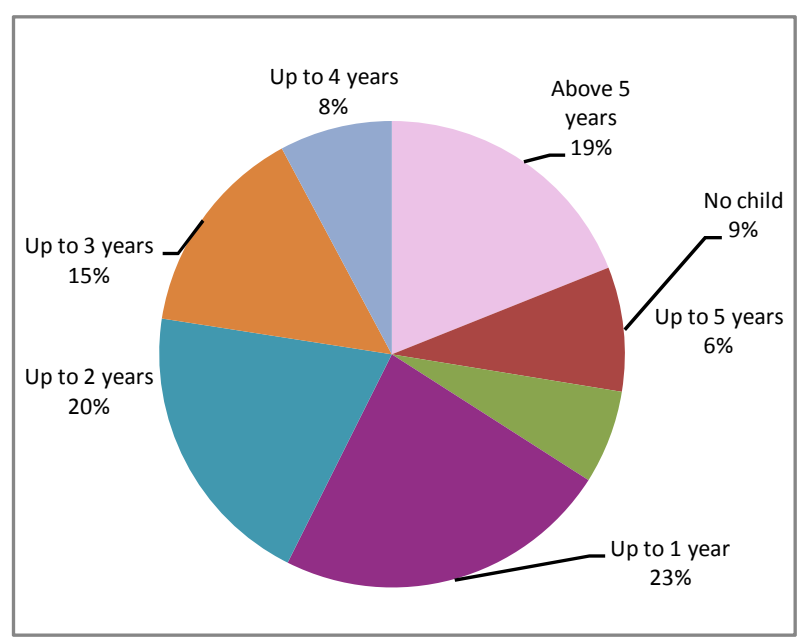

Figure 3.9: Percentage of WMRA by their desire for more children $(N=2093)$

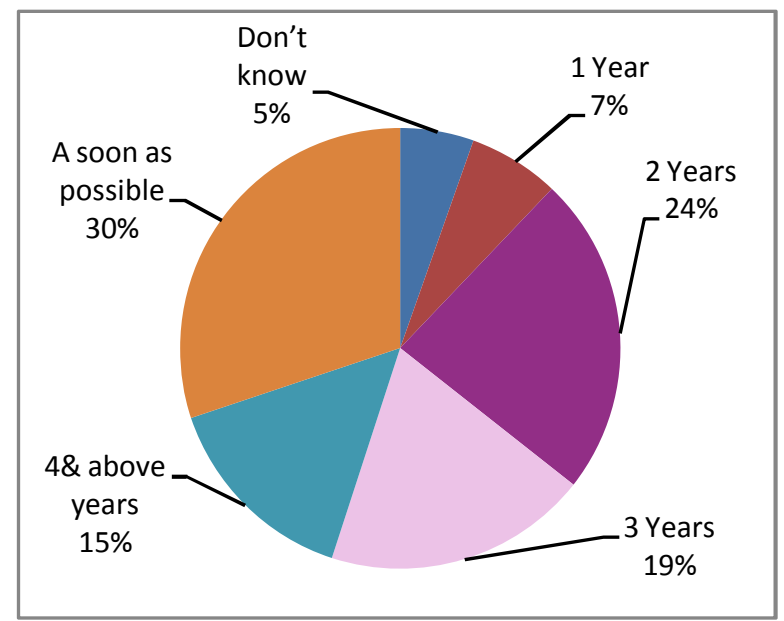




\section{Use of Contraceptive Methods}

Of all the respondents in our survey, nearly one fifth (18 percent) of the respondents were past users, whereas 43 percent had never used contraceptive methods. Nearly two fifths (39 percent) of the respondents reported that they were using contraceptives at the time of the interview, i.e. current users. Hence, the ever users (past + current users) were 57 percent and the contraceptive prevalence rate (CPR) was 39 percent, a number substantially higher than the national figure of 29 percent.

Figure 3.10: Percentage of MWRA by contra ceptive method use $(\mathrm{N}=2093)$

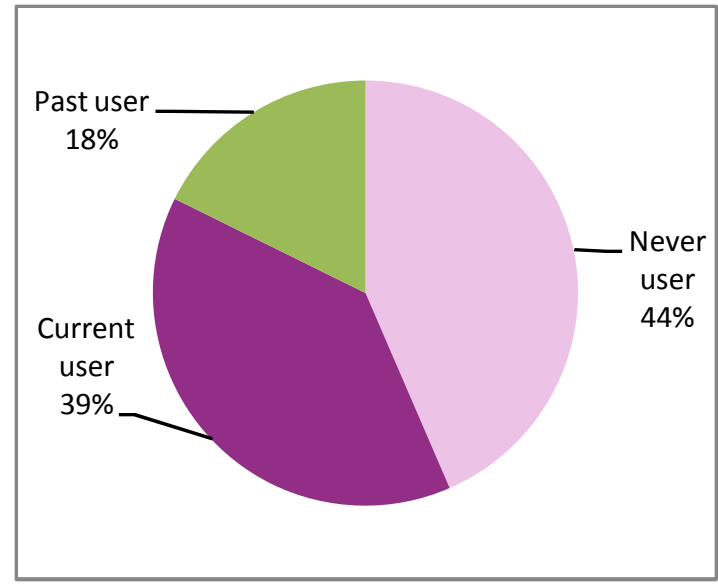

Figure 3.11: Contraceptive method $\operatorname{mix}(\mathrm{N}=812)$

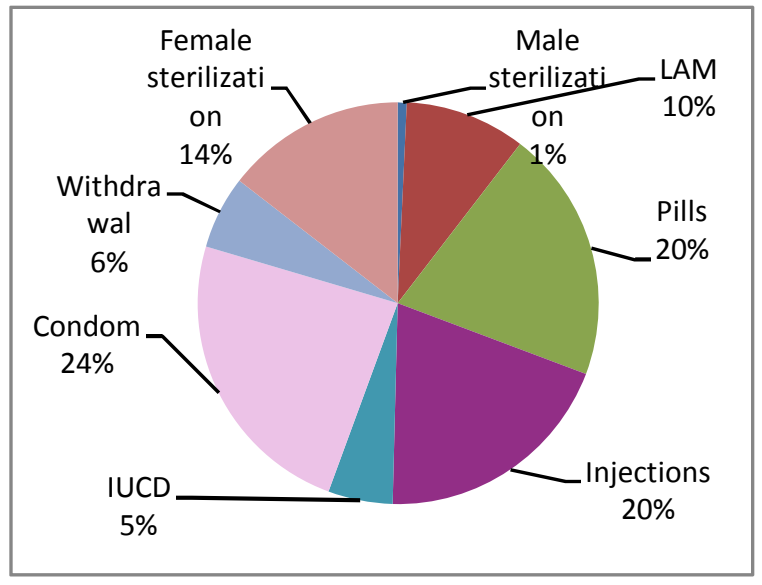

Method mix shows that a substantial majority of the current users (84 percent) were modern contraceptive users, whereas only 16 percent of the current users reported to use traditional methods. The most commonly reported methods were condoms (24 percent), pills (20 percent), injectables (20 percent) and female sterilization (14 percent).

\section{Current Knowledge of ECP Utility}

\section{Purpose}

A great majority of the respondents, 81 percent, had ever heard about the ECP. When asked about the purpose to use ECP, 73 percent of the respondents reported that it was used to avoid pregnancy after unsafe intercourse. However, 11 percent of the respondents did not know the purpose of ECP use.
Figure 3.12: Percentage of MWRA who heard about ECP by various purposes of ECP $(N=405)$

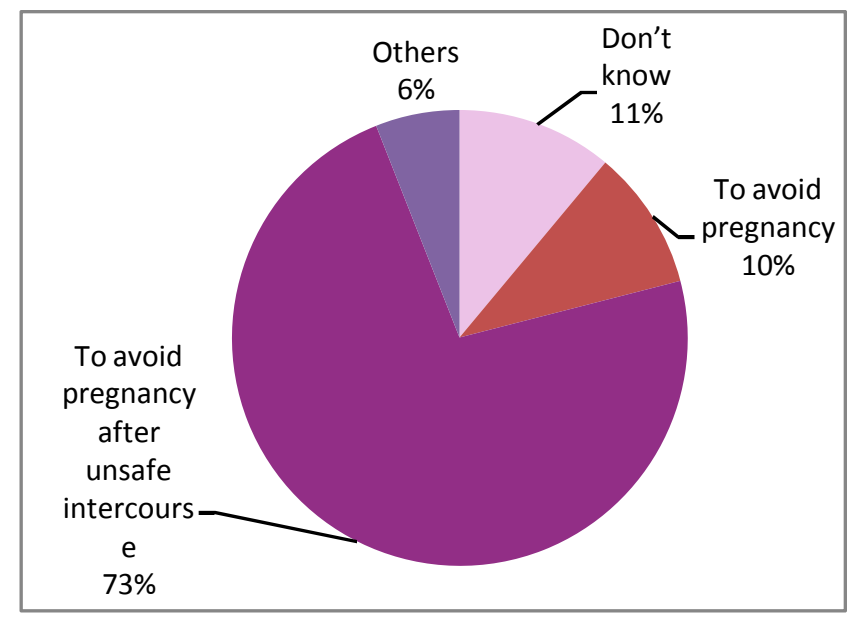




\section{Conditions to Use of ECP}

Regarding the various conditions for the use of ECP, slightly over half of the respondents (53 percent) stated that the ECP should be used when a woman either forgets to take her regular contraceptives or is late for next dose, while nearly one third of the respondents (31 percent) reported the ECP should be used after the ruptured of condom during intercourse.

Figure 3.13: Percentage of MWRA reported various conditions for ECP use $(N=405)$

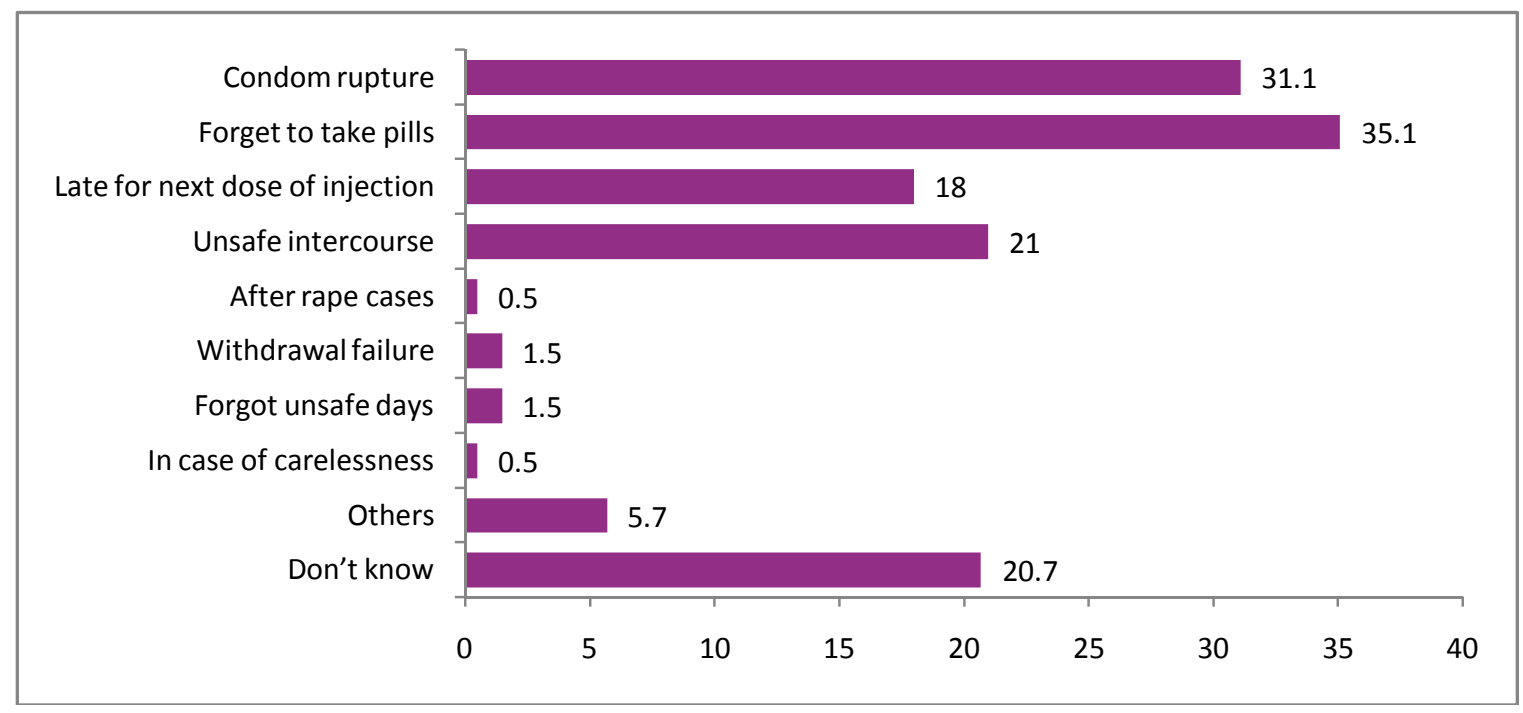

\section{Effective Duration of ECP}

When asked about the effective duration of the use of ECP after unsafe intercourse, more than one third of the respondents (37 percent) stated that the ECP should be used up to 120 hours after the unsafe intercourse, whereas 23 percent reported up to 72 hours after unsafe intercourse. However, another one third of the respondents (34 percent) did not know the exact duration.
Figure 3.14: Percentage of MWRA reported the duration of ECP use $(\mathrm{N}=405)$

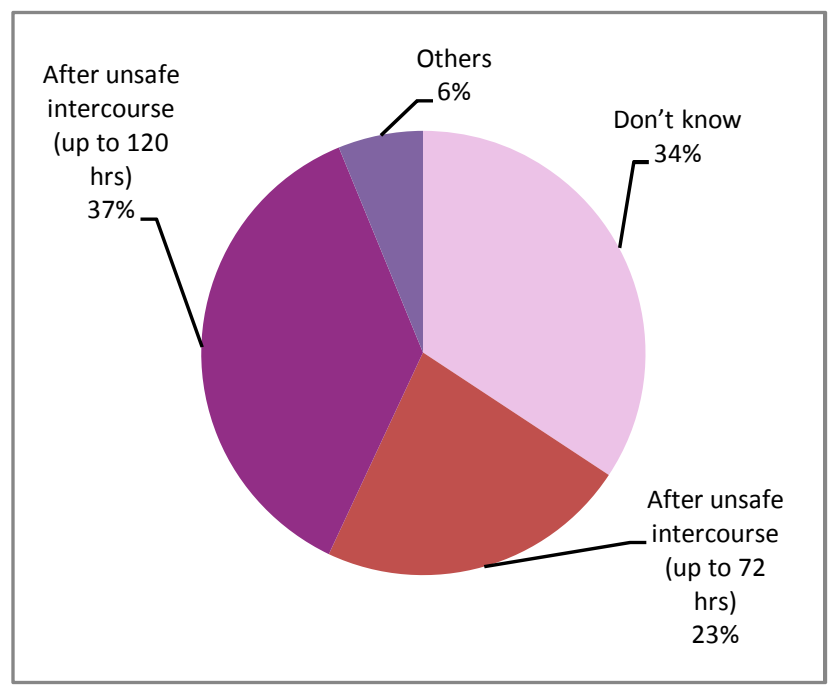




\section{Information about ECP Use}

More than two thirds of the respondents (69 percent) reported ECP as a safe method and half of the respondents (50 percent) stated that the ECP should not use as a regular contraceptive method. Forty three percent of the respondents said that there were no side effects associated with the ECP. When asked, 'if a woman is not sure about her pregnancy status, can she use ECP to avoid pregnancy?', forty six percent of the respondents stated that women should not use ECP. Two fifths of the respondents (40 percent) reported doing a pregnancy test, if a woman experienced delayed menstrual cycle after taking the ECP doses. The most common side effects associated with ECP use, reported by the respondents, were giddiness (47 percent), vomiting (42 percent), nausea (39 percent) and headache (30 percent).

Figure 3.15: Percentage of MWRA reported information about ECP use $(\mathrm{N}=405)$

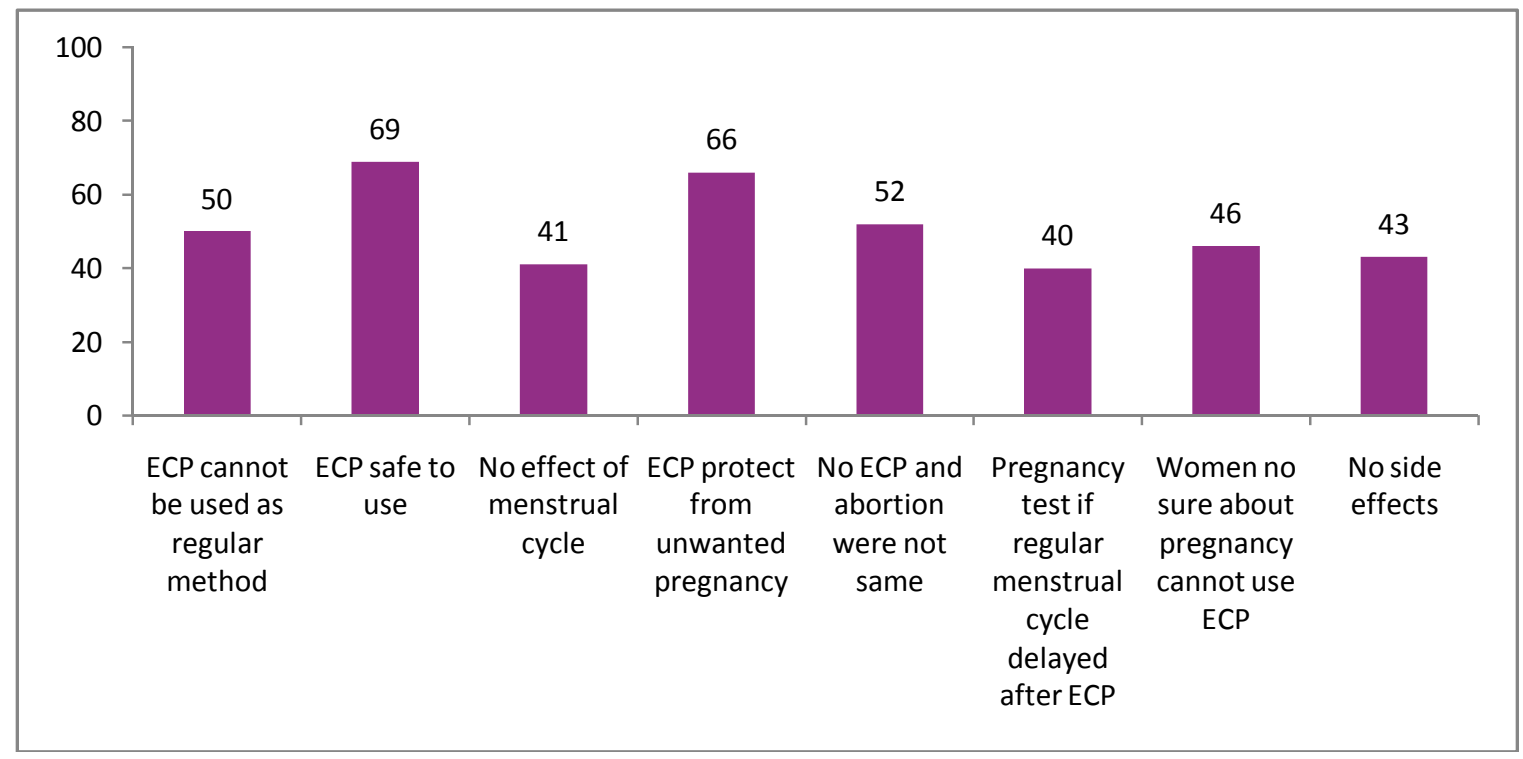

\section{Source of information}

When asked about the source of the above cited information, a substantial majority of the respondents (84 percent) reported that the LHWs of their communities informed them about the ECP, while 7 percent reported that they were informed by their friends/ relatives. Further, 3 percent of the MWRA got the information through mass media, i.e. TV.
Figure 3.16: Percentage of MWRA reported the source of information about ECP $(\mathrm{N}=405)$

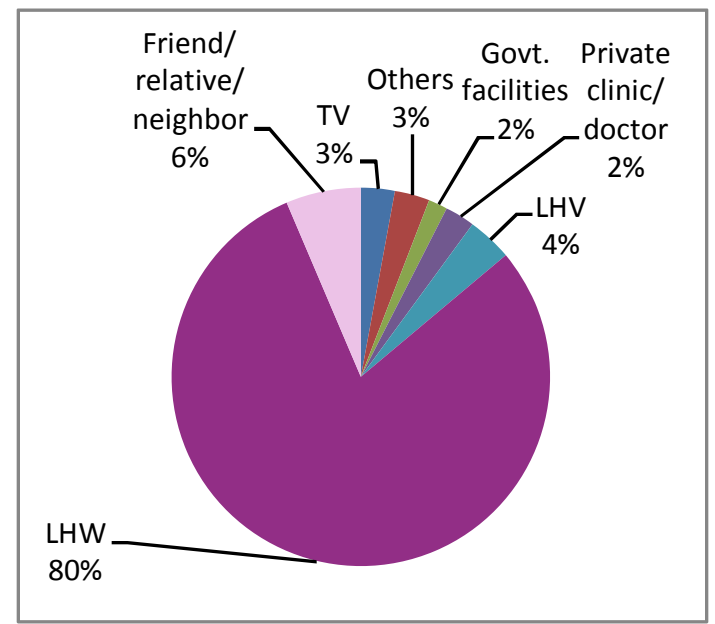




\section{Availability of ECP}

When asked about the easy availability of the ECP doses in their communities, a great majority of the respondents (80 percent) stated that one could easily obtain the ECP doses in their communities. The most common source of the ECP doses in their communities were the LHWs of their areas (84 percent), followed by medical store (22 percent) and government health facilities (BHU, RHC, DHQ and THQ hospitals) (7 percent).

Figure 3.17: Percentage of MWRA by easy availability of ECP $(\mathrm{N}$ = 405)

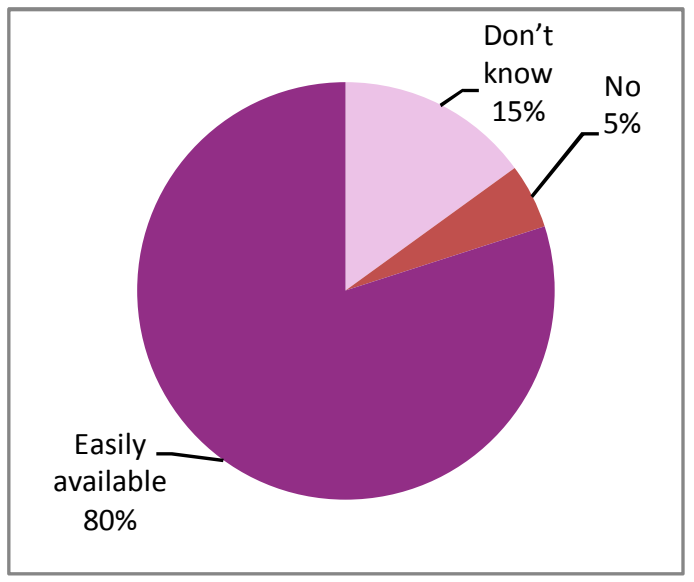

Figure 3.18: Percentage of MWRA by various sources of ECP in communities $(\mathrm{N}=$ 323)

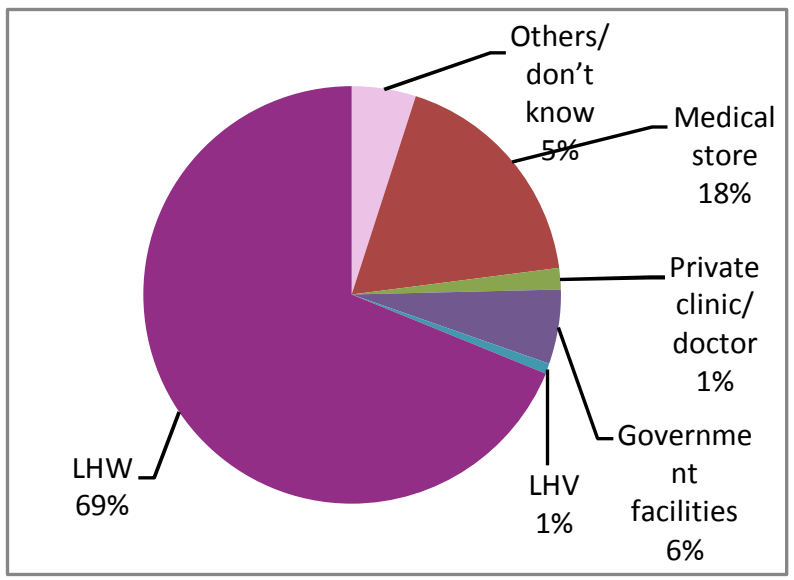

\section{ECP Users}

\section{Ever Use of ECP}

Twenty nine percent of the respondents reported ever using ECP. The most common reason for the use of ECP was rupture of condom during the intercourse (32 percent), followed by unsafe intercourse (27 percent), forgetting to take pills (20 percent) and being late for next dose of injection (10 percent). 
Figure 3.19: Percentage of MWRA by ever use of ECP $(N=405)$

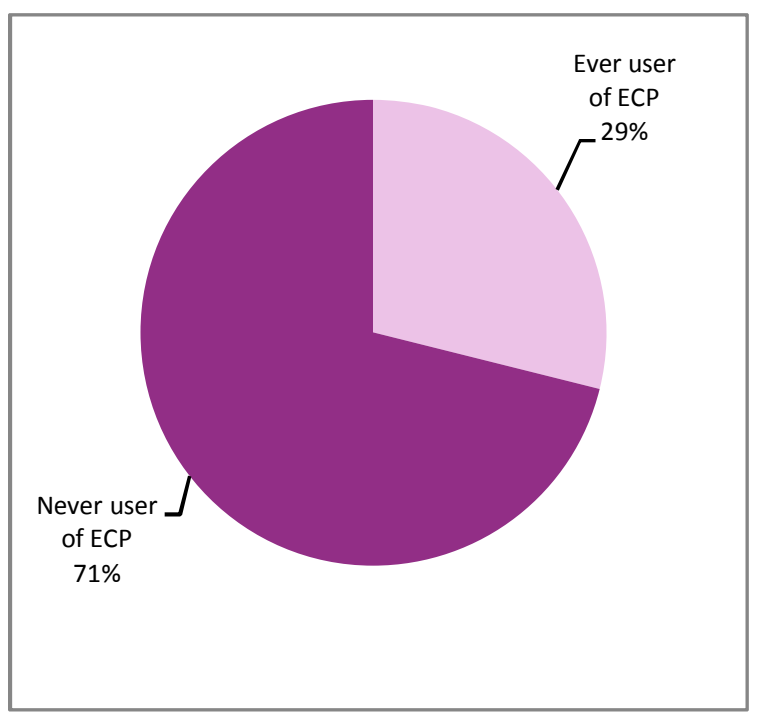

Figure 3.20: Percentage of MWRA by various reasons for ECP use $(\mathrm{N}=117)$

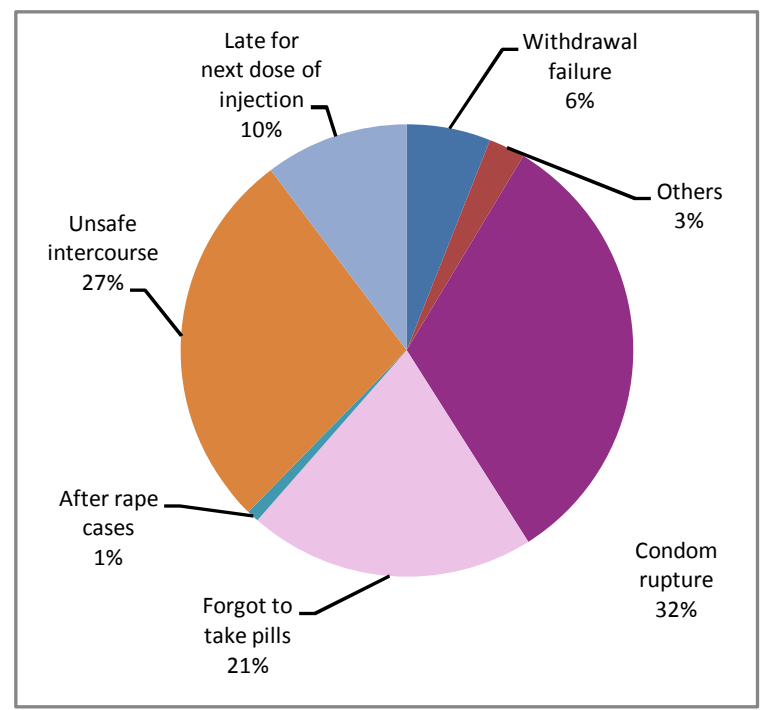

\section{Source of ECP}

All the respondents who reported ever using ECP $(n=117)$, were asked about the source from where they got the ECP doses last time. A great majority of the respondents (81 percent) obtained ECP doses from the LHWs in their community when they used it last time. However, 13 percent of the respondents obtained it from a medical store while 2 percent got it from government health facilities (BHU, RHC, THQ and DHQ hospitals).

Figure 3.21: Percentage of MWRA by source of ECP $(\mathrm{N}=117)$

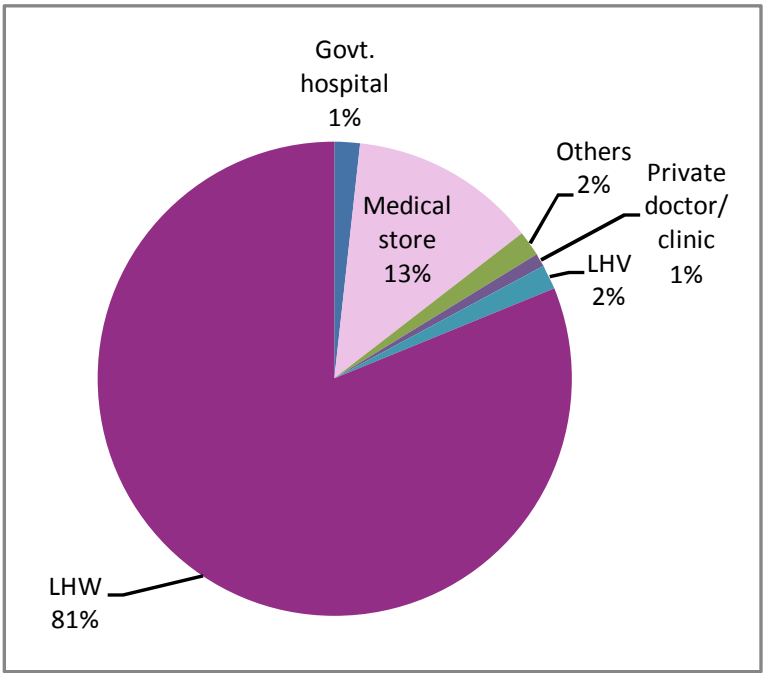

Figure 3.22: Percentage of MWRA by time needed to obtain ECP $(\mathrm{N}=117)$

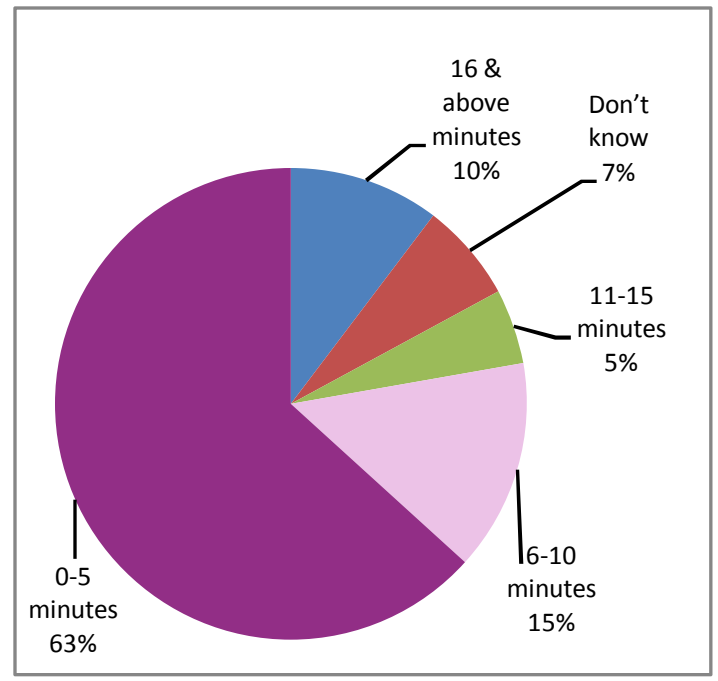

As majority of the respondents obtained the ECP doses from the LHWs of their areas, therefore, more than three quarters of the respondents (78 percent) stated the time interval as up to 10 minutes from their houses to providers to get the ECP doses. 


\section{Cost of ECP}

A substantial majority of the respondents (82 percent) who reported ever using ECP obtained the ECP doses free of cost as the LHWs provided the ECP doses free of cost to all the MWRA in their communities. Only 9 percent of the respondents made payments (8 and 50 rupees) to obtain ECP doses. When asked about whether the ECP was expensive or not, 72 percent of the respondents reported it was not expensive.

Figure 3.23: Percentage of MWRA by cost of ECP $(\mathrm{N}=117)$

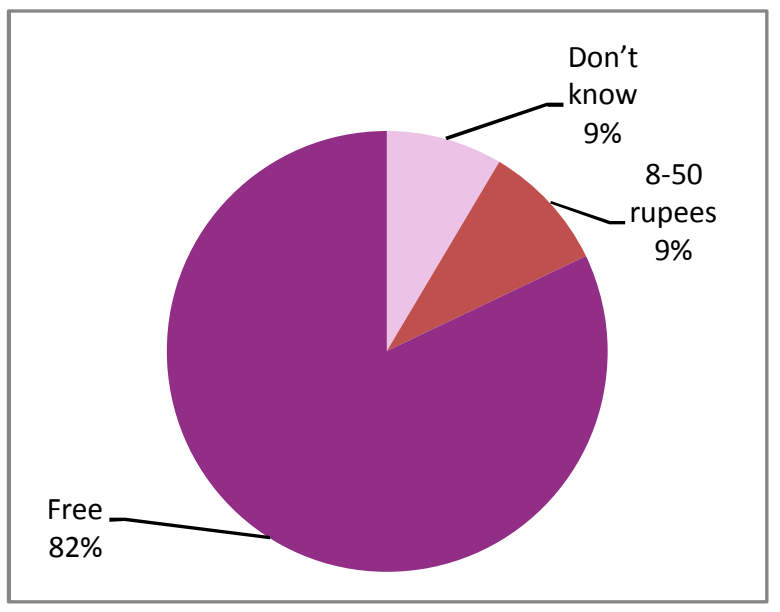

\section{Number of Doses of ECP Used}

When asked about how many doses of ECP they used during the last month before the survey, women who reported using ECP, slightly over three fifths of the respondents (61 percent) did not use it previous month, while 27 percent of the respondents used one dose during the previous month and 6 percent each used it two and three times during the month before the survey.
Figure 3.24: Percentage of MWRA reported whether ECP expensive or not $(\mathrm{N}=117)$

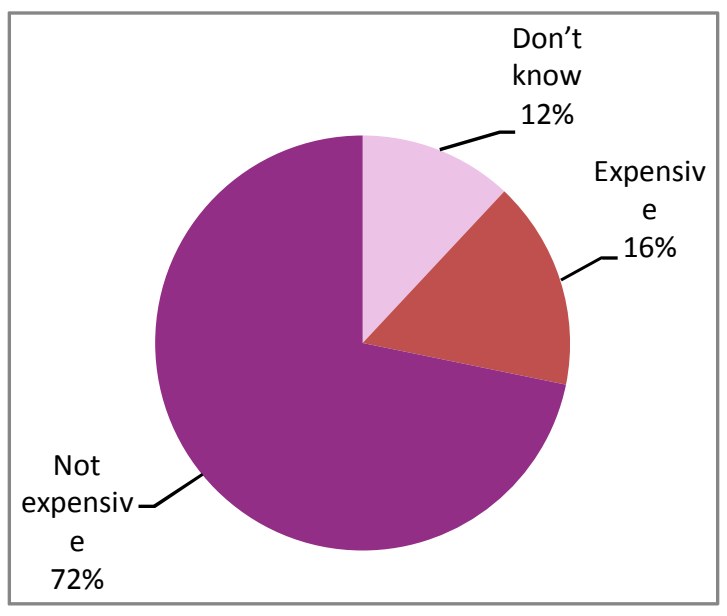

Figure 3.25: Percentage of MWRA by number of doses of ECP used last month $(N=117)$

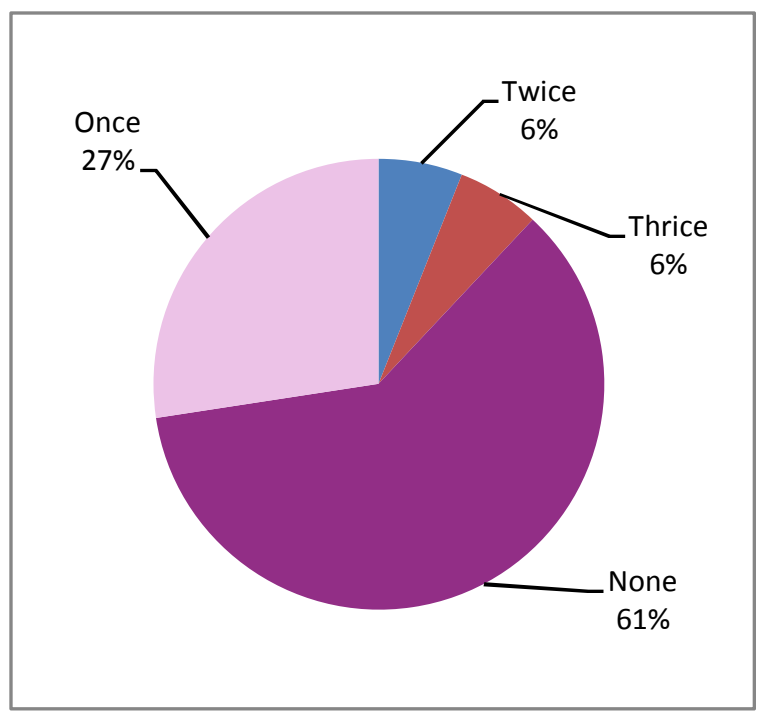




\section{Effectiveness of ECP}

Regarding the effectiveness of the ECP doses when the respondents used it last time, a substantial majority of the respondents (95 percent) stated that it was effective, while 5 percent of the respondents reported that the use of ECP was not effective, as their pregnancies were not avoided.

\section{Experienced Side Effects Associated with ECP}

Figure 3.26: Percentage of MWRA by

effectiveness of ECP $(N=117)$

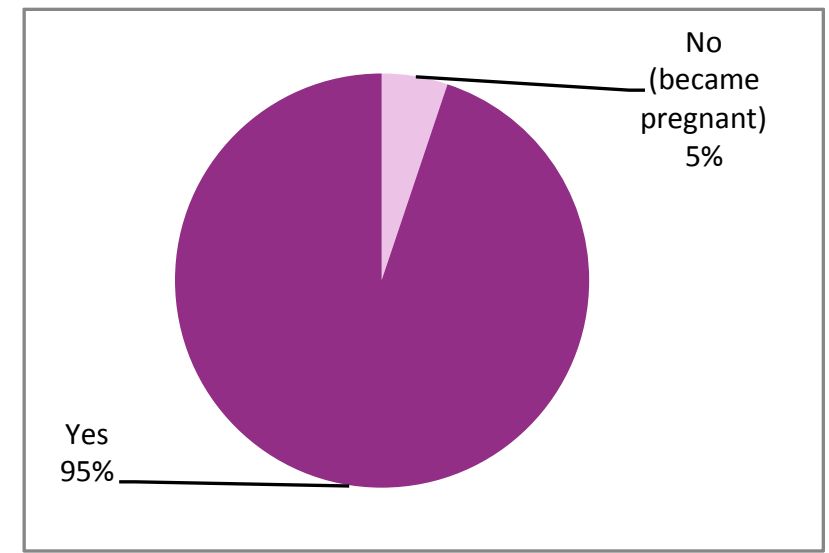

Regarding experiencing the side effects associated with the ECP, slightly over one fifth of the respondents (21 percent) reported experiencing side effects after the use of ECP. The most common side effects experienced were headache and giddiness (52 percent each), followed by vomiting (24 percent), weakness and irregularity in periods (16 percent each).

Figure 3.27: Percentage of MWRA by experiencing various side effects $(\mathrm{N}=\mathbf{2 5})$

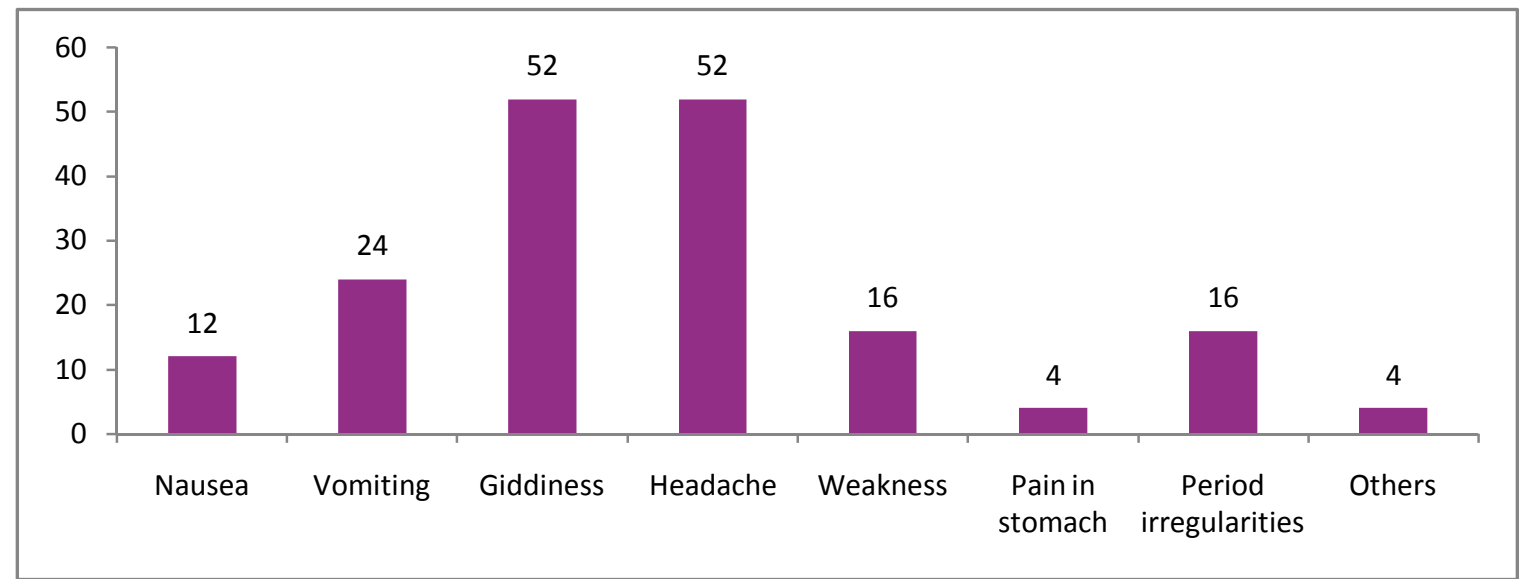




\section{Management of Side Effects}

When those women who experienced side effects after the use of ECP were asked about the management of side effects, three fifths of the respondents (60 percent) reported that they contacted the providers for the management of side effects after the use of ECP.

\section{Figure 3.28: Percentage of MWRA by} contacting the providers for the management of side effects $(\mathrm{N}=$ 25)

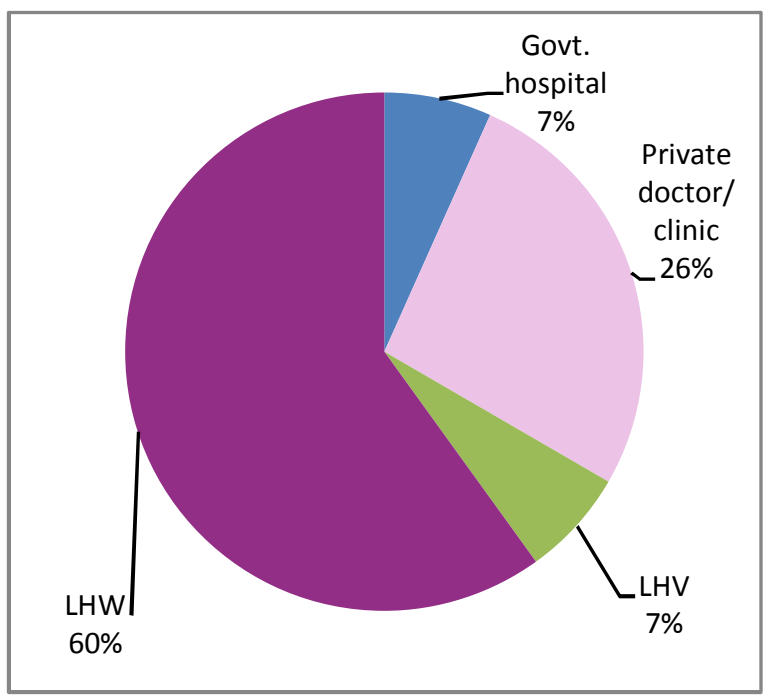

Figure 3.29: Percentage of MWRA by contacting various providers for the management of side effects $(\mathrm{N}$ = 15)

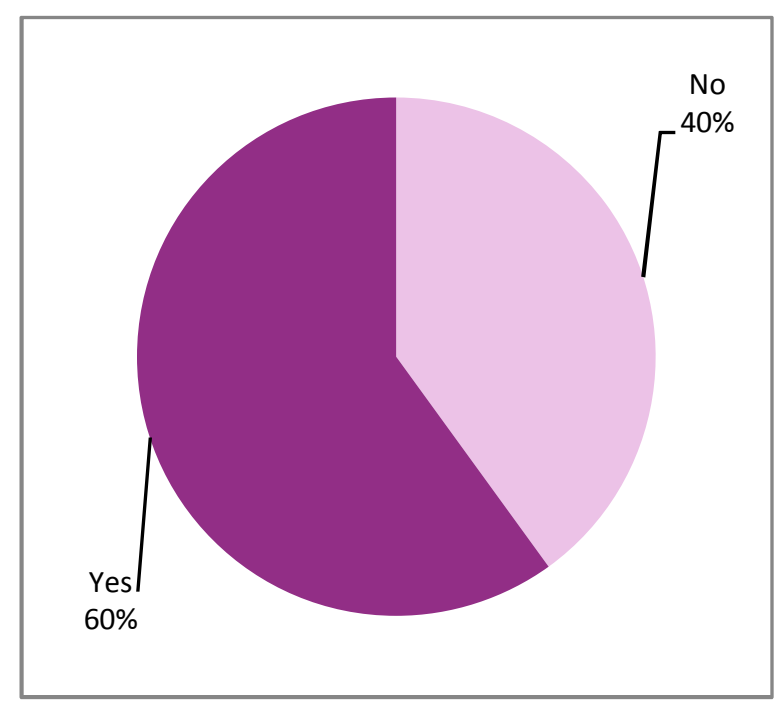

Out of those who contacted, three fifths of the respondents (60 percent) stated to contact the LHWs of their communities, while 27 percent got in touch with private doctors/ clinics. Furthermore, those women who contacted the LHWs for the management of the side effects after taking the ECP doses, one third of them (33 percent) were referred to the health facility for the management of the side effects, mostly to the government health facilities.

\section{Advice to Others and Desire to Use in Future}

When those who reported use of ECP were asked about their advice to other women about the use of ECP in case of emergency, a substantial majority (95 percent) would like to advise other women to use ECP in case of emergency. Likewise, slightly over four fifths of the ever users of ECP (81 percent) stated that they would like to use ECP (if required) in future. 
Figure 3.30: Percentage of MWRA who would recommend ECP to others $(\mathbf{N}=117)$

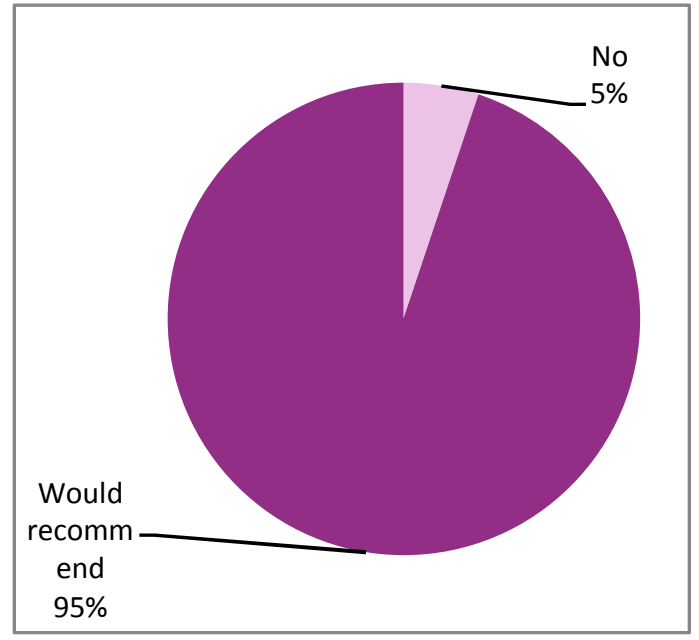

Figure 3.31: Percentage of MWRA by their desire to use ECP in future $(\mathrm{N}=117)$

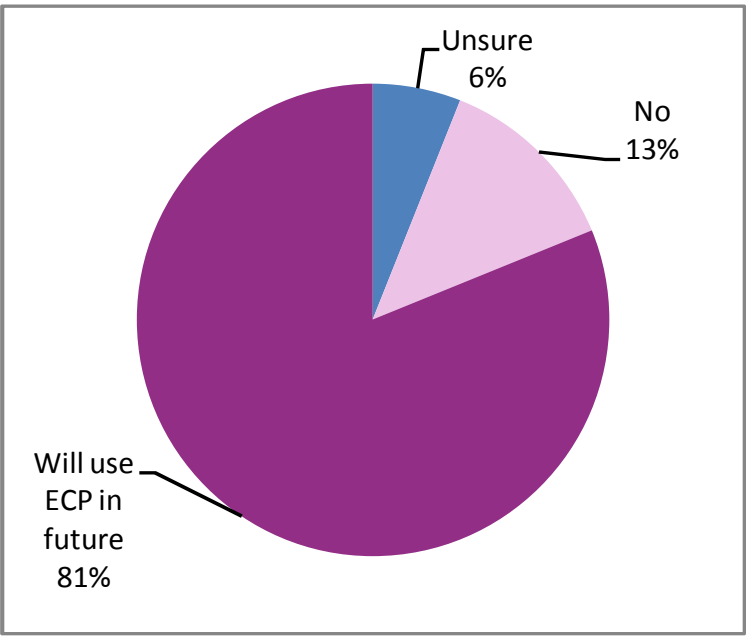





\section{Chapter 4: Conclusions AND Recommendations}

The following conclusions and recommendations have emerged from the current evaluation study of the program entitled "Introduction of ECP through LHW Program in Pakistan":

- LHWs, the community based health workers, are the primary contact persons for health and family planning services in resource poor communities of Pakistan and our findings show that it is feasible to introduce ECP through NP for FP \& PHC (LHW program) in Pakistan.

- The training process, including the training material and methodology developed by the Population Council in concurrence with NP for FP \& PHC, implemented by the program management (using its existing training cascade) shows an effective impact on the retention of knowledge and practice of LHWs regarding the ECP in their communities. Therefore, it is recommended that the ECP program should be scaled up throughout the country using the LHW program in a phased manner. However, there is a need for supportive monitoring and periodic evaluation of the training process.

- LHWs do not have regular supplies of the ECP doses, as highlighted by the current study. Therefore, keeping in mind the demand of the ECP in the communities, it is recommended that ECP doses should be included as part of the contraceptive methods provided by the LHWs in their communities. A mechanism should be developed to supply the ECP doses by involving other donors like UNFPA on the regular basis to all the trained LHWs.

- Nearly one third of the women reported ever using ECP. This shows quite a high demand of the ECP in our communities. Further, our results show that the effectiveness of the ECP (avoiding pregnancies after unsafe intercourse) is also substantially high (95 percent) in our communities. Therefore, introducing the ECP at community level through community based health workers program (LHW program) can reduce the number of induced abortions in Pakistan.

- Majority of women who ever used ECP are currently using other modern methods such as condoms, pills etc. This shows that rupture of condom during intercourse and delay in the next dose of pills and injectables leads to failure of the method. Therefore, it is recommended that the LHWs while providing these contraceptives to the clients should also advise them to use ECP in case of emergency.

- Similarly, majority of women who reported ever use of ECP do not want more children in future or want to wait for at least 3 years for their next child and are 
currently using some modern contraceptive method to avoid pregnancy. This shows that there is high unmet need for the ECP in Pakistan.

- The current level of knowledge of MWRA regarding ECP utility is not up to the mark. Therefore, while introducing the ECP through the LHW program in Pakistan, there is a need for the effective advocacy and community mobilization as a part of the program. LHWs should mobilize women in their areas and provide necessary information. Likewise, mass media, such as television, is an effective means of informing women about the ECP and should be included in the Program's scaling up. 


\section{REFERENCES}

ADHIKARI, R. 2009. Factors affecting awareness of emergency contraception among college students in Kathmandu, Nepal. BMC Women's Health, 9, 27 - 31.

BONGAARTS, J. 1997. Trends in Unwanted Childbearing in the Developing World. Studies in Family Planning, 28, 267 - 277.

CONSORTIUM FOR EMERGENCY CONTRACEPTION 2000. Expanding Global Access to Emergency Contraception: A collaborative approach to meeting women's needs. Seattle: Consortium for Emergency Contraception.

INTERNATIONAL CONSORTIUM FOR EMERGENCY CONTRACEPTION 2004. Emergency Contraceptive Pills. Washington DC: ICEC.

KHAN, A. G. 2010. Pakistan Report, 2010 Islamabad: Ministry of Population Welfare Islamabad and Population Communication, New York.

KHAN, M. E., HOSSAIN, A. M. I. \& REHMAN, M. 2004. Introduction of emergency contraception in Bangladesh: using operations research for policy decision. Dhaka: Population Council.

NIPS \& MACRO 2008. Pakistan Demographic and Health Survey 2006-07. Islamabad: National Institute of Population Studies Islamabad, Pakistan and Macro International Inc. Calverton, Maryland USA.

NISAR, Y. B. 2008. Corrections needed to Pakistani programme details. Bulletin of the World Health Organization, 86, B.

OXFORD POLICY MANAGEMENT 2009. Lady Health Worker Programme: Fourth External Evaluation for the National Programme for Family Planning and Primary Health Care. Quantitative Survey Report. Islamabad: Oxford Policy Management.

PIAGGIO, G., VON HERTZEN, H., GRIMES, D. A. \& VAN LOOK, P. F. 1999. Timing of Emergency Contraception with Levonorgestrel or the Yuzpe Regimen. Lancet, $353,721$.

POPULATION COUNCIL 2004. Unwanted Pregnancies and Post-Abortion Complications in Pakistan: Findings from a National Study. Islamabad: The Population Council.

SATHAR, Z. A. 2007. Stagnation in Fertility Levels in Pakistan. Asia-Pacific Population Journal, 22, 113 - 131.

SCHWARZ, E., GERBERT, R. \& GONZALES, R. 2007. Need for emergency contraception in urgent care settings. Contracpetion, 75, 285 - 288. 
SEBASTIAN, M. P., KHAN, M. E., KUMAR, S., SHEKHAR, C. \& GUPTA, N. K. 2005. Studying the Utilization of Emergency Contraceptive Services through Paramedics in India. Research Update, 5.

SEGAL, S. J. \& LAGUARDIA, K. D. 1990. Termination of Pregnancy: A global view. Balliere's Clinical Obstetric and Gynecology, 4, 235 - 247.

WHO 2004. Unsafe abortion-Global and regional estimates of the incidence of unsafe abortion and associated mortality in 2004. 4th ed. Geneva: Word Health Organization.

WHO/SEARO 2001. Making Pregnancy Safer. Delhi: World Health Organiation/SEARO. 